\title{
Nitroso-Redox Balance and Mitochondrial Homeostasis Are Regulated by STOX1, a Pre-Eclampsia-Associated Gene
}

\author{
Ludivine Doridot, ${ }^{1,2,{ }^{*}}$ Laurent Châtre ${ }^{3,4,{ }^{*}}$ Aurélien Ducat, ${ }^{1,2}$ Jean-Luc Vilotte, ${ }^{5}$ Anne Lombès, ${ }^{1,2}$ \\ Céline Méhats, ${ }^{1,2}$ Sandrine Barbaux, ${ }^{1,2}$ Rosamaria Calicchio,, Miria Ricchetti, ${ }^{1,4, \dagger}$ and Daniel Vaiman ${ }^{1,2, \dagger}$
}

\begin{abstract}
Aims: Storkhead box 1 (STOX1) is a winged-helix transcription factor that is implicated in the genetic forms of a high-prevalence human gestational disease, pre-eclampsia. STOX1 overexpression confers pre-eclampsia-like transcriptomic features to trophoblastic cell lines and pre-eclampsia symptoms to pregnant mice. The aim of this work was to evaluate the impact of STOX1 on free radical equilibrium and mitochondrial function, both in vitro and in vivo. Results: Transcriptome analysis of STOX1-transgenic versus nontransgenic placentas at 16.5 days of gestation revealed alterations of mitochondria-related pathways. Placentas overexpressing STOX1 displayed altered mitochondrial mass and were severely biased toward protein nitration, indicating nitrosoredox imbalance in vivo. Trophoblast cells overexpressing STOX1 displayed an increased mitochondrial activity at $20 \% \mathrm{O}_{2}$ and in hypoxia, despite reduction of the mitochondrial mass in the former. STOX1 overexpression is, therefore, associated with hyperactive mitochondria, resulting in increased free radical production. Moreover, nitric oxide (NO) production pathways were activated, resulting in peroxynitrite formation. At low oxygen pressure, STOX1 overexpression switched the free radical balance from reactive oxygen species (ROS) to reactive nitrogen species (RNS) in the placenta as well as in a trophoblast cell line. Innovation: In pre-eclamptic placentas, NO interacts with ROS and generates peroxynitrite and nitrated proteins as end products. This process will deprive the maternal organism of NO, a crucial vasodilator molecule. Conclusion: Our data posit STOX1 as a genetic switch in the ROS/RNS balance and suggest an explanation for elevated blood pressure in pre-eclampsia. Antioxid. Redox Signal. 21, 819-834.
\end{abstract}

\section{Introduction}

$\mathbf{P}$ RE-ECLAMPSIA, A WIDESPREAD disease of pregnancy, affects $2 \%-8 \%$ of women (66) and is responsible for 50,000 maternal deaths worldwide (9). This syndrome, characterized by de novo hypertension and proteinuria, is considered to originate from placental defects (35). Usually, uterine arteries are invaded by extra-villous cytotrophoblasts that reach the first third of the myometrium, replace maternal endothelial cells and, ultimately, adopt an endothelial phenotype. Consistently, oxygen pressure progresses from 1.5 $2 \%$ during early gestation to around $10 \%$ at late time points
(33). In pre-eclamptic pregnancies, maternal uterine arteries are not deeply colonized, resulting in insufficient or irregular blood flow to the fetus (25). A landmark of hypoxia, the hypoxia-inducible miRNA miR-210 (15), is up-regulated in pre-eclampsia (32). Transitory local hypoxic/hyperoxic changes exceedingly erode the syncytiotrophoblast and shed debris into maternal circulation. These debris release vasoactive substances such as endothelin 1 (55) and antiangiogenic factors (notably sFLT-1 and sENG), thus contributing to the maternal systemic endothelial injury.

Reactive oxygen species (ROS) and reactive nitrogen species (RNS) have been associated with pre-eclampsia (46,

\footnotetext{
${ }^{1}$ Department of Development, Reproduction, and Cancer, Institut Cochin, INSERM U1016, Paris, France.

${ }^{2}$ CNRS UMR8104, Faculté Paris Descartes, Paris, France.

${ }^{3}$ Unité de Génétique Moléculaire des Levures, Institut Pasteur, Paris, France.

${ }^{4}$ Team Stability of Nuclear and Mitochondrial DNA, CNRS UMR 3525, Paris, France.

${ }^{5}$ INRA, UMR1313 Génétique Animale et Biologie Intégrative, Institut Nationale de la Recherche Agronomique, Jouy-en-Josas, France.

*These authors contributed equally to the experiments presented in this article.

${ }^{\dagger}$ These authors contributed equally to the management of the research presented in this article.
} 


\section{Innovation}

In this study, we show that a unique transcription factor, storkhead box 1 (STOX1), induces opposite $\mathrm{O}_{2}$-dependent effects on reactive oxygen species (ROS) and reactive nitrogen species (RNS) production in vitro as well as in vivo in a murine model of pre-eclampsia. We show a striking predominance of RNS in STOX1 transgenic placentas, suggesting that NO is rapidly associated with ROS and generates $\mathrm{ONOO}^{-}$. This would deprive endothelial cells from the essential vasodilating action of $\mathrm{NO}$, thereby giving a rationale to the systemic hypertension of mice with transgenic (pre-eclamptic) placentas. Nitroso-redox imbalance could be considered the causative element in pre-eclampsia-induced hypertension and other vascular diseases. These observations may have implications for human pathogenesis and therapeutics.

57, 74). Mitochondrial mass (mitochondria being major sources of ROS/RNS) is increased in pre-eclamptic placentas (72). However, when cytotrophoblast cells are isolated from these defective placentas, the expression of mtDNA and nuclear respiratory factor 1 (NRF1) (linked to the mitochondrial mass) is abnormally low (43). Proteomics analysis of severe pre-eclamptic placentas revealed altered mitochondria-related pathways such as fatty acid oxidation (4), ROS generation, and oxidative stress (64).

Overexpression of the storkhead box 1 (STOX1) transcription factor (71) induces transcriptome alteration, mimicking pre-eclampsia in choriocarcinoma JEG-3 cells, used as proxies for trophoblast cells (56), and induces a preeclampsia-like syndrome in vivo in a transgenic mouse model (18). Major transcriptome alterations in cells overexpressing STOX1 involve several cellular pathways, among which the mitochondrial function is highly represented (56). This prompted us to further investigate how STOX1 regulates the mitochondrial function and ROS/RNS balance. In the present study, STOX1 overexpression in transgenic placentas and trophoblast cells strongly altered the ROS/RNS metabolism and mitochondrial function. The novel transcription factor STOX1 appears as a major regulator of the nitroso-redox balance and mitochondrial homeostasis, possibly depriving the maternal vascular system of nitric oxide (NO), a major agent of endothelium health. In cells overexpressing STOX1, the major hypoxamir miR-210 (29) is virtually extinguished, suggesting that trophoblast cells become unable to adapt to low $\mathrm{O}_{2}$ concentration.

\section{Results}

STOX1 placentas display massive deregulation of genes involved in mitochondrial function

The transcriptomes of 16.5 days post fertilization (dpc) transgenic versus wild-type (WT) placentas were compared, using Gene Set Enrichment Analysis (GSEA, see Materials and Methods section). Among 962 gene groups or pathways analyzed, 373 were identified as significant (false discovery rate [FDR] <0.25). Strikingly, 12 out of 13 mitochondriarelated pathways belonged to this group $\left(p=6.6 \times 10^{-5}\right.$, with FDR ranging from 0.017 to 0.21 ). The list of pathways and gene groups is provided in Supplementary Table S1 (Supplementary Data are available online at www.liebertpub.com/ ars). As an example, genes relevant to the cluster "Mitochondrial Part" are listed in Supplementary Figure S1, and Supplementary Table S2. In sum, major alterations of gene expression in STOX1 transgenic placentas at 16.5 days of gestation clearly targeted mitochondria, confirming the data obtained in the cellular model.

\section{STOX1 overexpression in transgenic placentas induces altered mitochondrial mass and nitroso-redox imbalance}

The mitochondrial mass, evaluated by the steady-state immunofluorescence of the outer membrane mitochondrial marker TOM22 (39), was significantly higher (approximately fourfold) in pre-eclamptic than in control placentas, at least in the Labyrinth and the Junctional zone (Fig. 1A, B), similar to what is observed in human pre-eclamptic placentas (43). TOM22 (and porine voltage-dependent anion channel [VDAC]) global increase in pre-eclamptic placentas was confirmed by Western blots (Fig. 1C). This result prompted us to analyze free radical production in placentas. For this, we evaluated the steady-state levels of protein oxidative adducts, either (ROSdependent) carbonylation or (RNS-dependent) nitration (65, 69), using dinitrophenyl or 3-nitrotyrosine immunostaining, respectively. We observed a striking signal inversion between transgenic and nontransgenic placentas (Fig. 1D, E). Transgenic placentas displayed dramatically higher levels of nitrated proteins and lower levels of carbonylated proteins than controls, in each placental compartment. These in vivo results point to STOX1 as a crucial regulator of the nitroso-redox balance in the placenta.

\section{STOX1 overexpression deregulates genes involved in the response to hypoxia, redox balance, nitric oxide, and energy metabolism}

We then analyzed gene expression in JEG-3 trophoblasts [control and STOX1High, obtained in a previous study (56)] by RT-qPCR; primers are described in Supplementary Table S3. Since oxygen is a signaling molecule in trophoblasts (11), we cultivated both cell types at either $2 \%$ or $20 \% \mathrm{O}_{2}$. Two percent $\mathrm{O}_{2}$ is compatible with oxygen concentrations of early gestation. Twenty percent $\mathrm{O}_{2}$, higher than natural oxygen concentrations, was, nevertheless, chosen to compare our results with most available studies based on trophoblasts cultivated at atmospheric pressure. STOX1High cells expressed STOX1 at a high level in both conditions (Fig. 2A).

STOX1High cells in hypoxia recapitulated metabolic alterations observed in pre-eclampsia, as decreased DNA damage response (DDR) (Supplementary Fig. S2A), and decreased expression of genes involved in cholesterol metabolism, SREBPIA, and SREBPIC (28) (Supplementary Fig. S2B).

At $2 \% \mathrm{O}_{2}$, expression of the two crucial modulators of the hypoxia response $H I F 1 \alpha$ and $H I F 1 \beta$ was moderately affected by hypoxia (Fig. 2A). The hypoxamir miR-210 levels were not altered in STOX1 overexpressing cells at 20\% $\mathrm{O}_{2}$. Strikingly, however, at $2 \% \mathrm{O}_{2}$ miR-210 expression increased by $\sim 6$-fold in control cells and decreased by $\sim 30$-fold in STOX1High cells compared with $20 \% \mathrm{O}_{2}$, resulting in a dramatically reduced level $(\sim 180$-fold $)$ of miR-210 in STOX1High cells under hypoxia. 

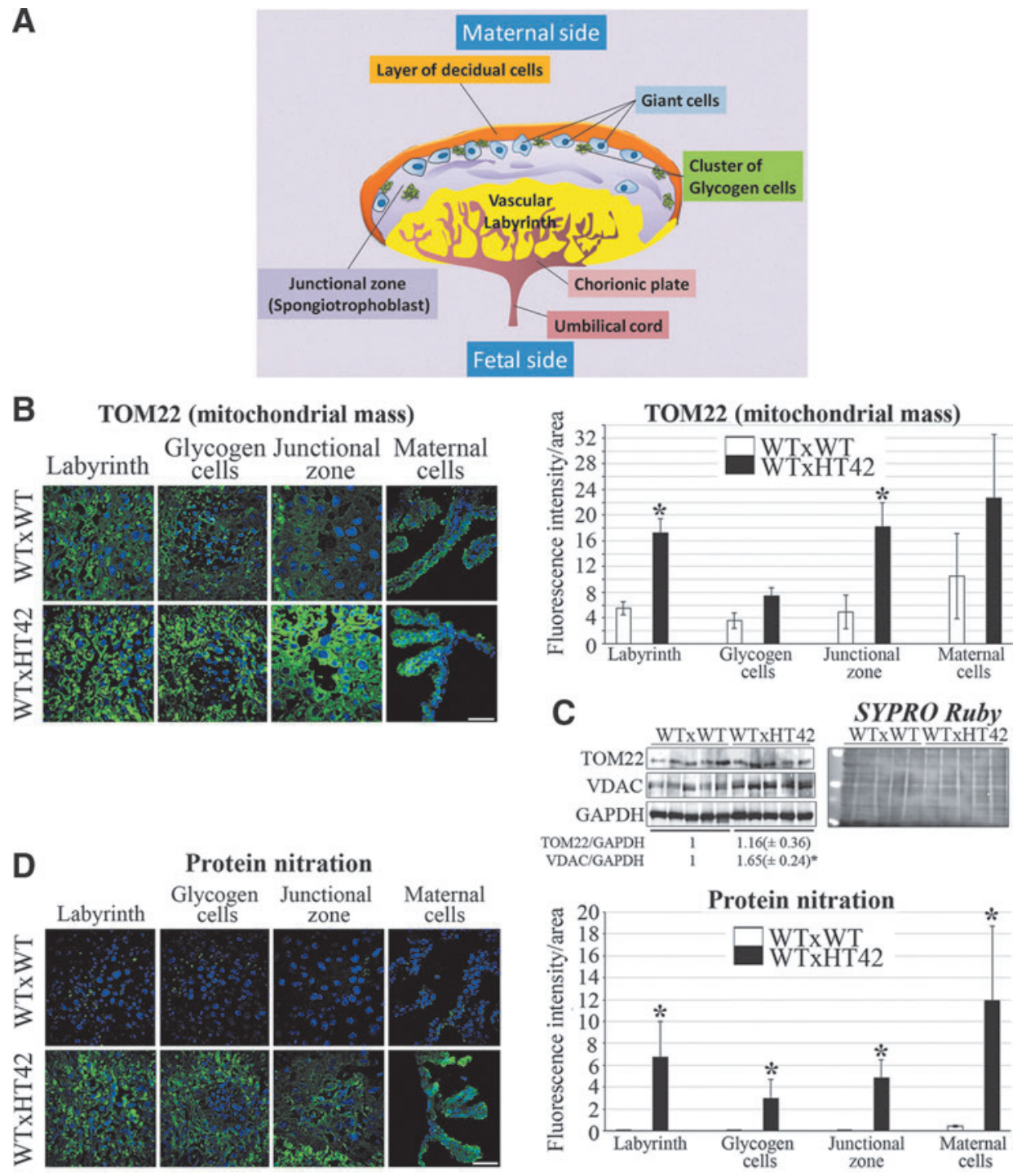

E Protein carbonylation
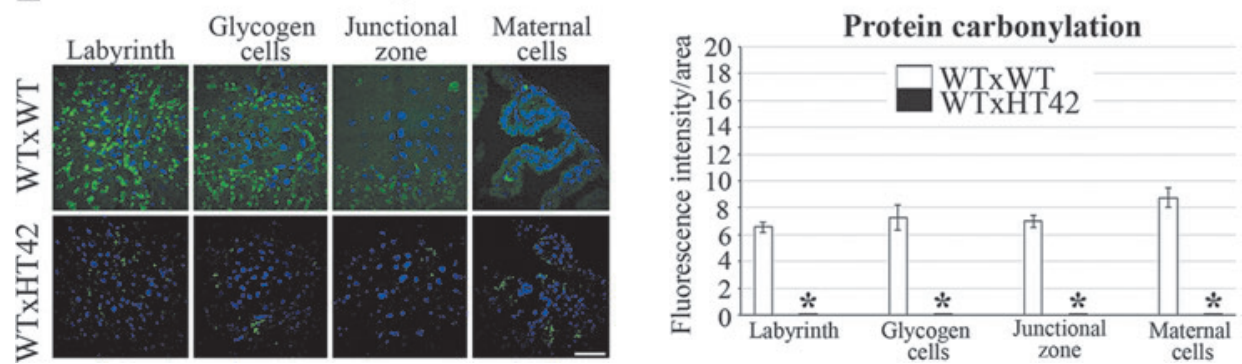

FIG. 1. In vivo alterations of mitochondria and nitroso-redox balance in transgenic STOX1 overexpressing placentas. (A) Structure of the murine placenta. (B) Three-dimensional-reconstructed placenta regions (Labyrinth, Glycogen cells, Junctional zone, and Maternal cells) stained with TOM22 (green) and counterstained with Hoechst in mice from WT $\times$ WT and WT $\times$ TgSTOX42 crosses. Right panels indicate fluorescence intensity quantification per surface (area) analyzed; identical surfaces were assessed in all samples; $n=500$ surfaces (Labyrinth), and $n=100$ surfaces (Glycogen cells, Junctional zone, and Maternal cells) per tissue section. Scale bar $=50 \mu \mathrm{m}$. (C) Western blot of mitochondrial markers TOM22 and VDAC, of internal reference GAPDH, and of stained membrane with loading control SYPRO Ruby on protein extracts from five WT $\times$ WT and five WT $\times$ HT42 placentas, with quantification by densitometry. Despite the blurring due to the presence of several cell types in the placentas, the difference was significant at $p<0.05$ with VDAC (asterisk). (D, E) Three-dimensional-reconstructed placenta regions (Labyrinth, Glycogen cells, Junction zone, and Maternal cells) stained with (D) 3-nitrotyrosine antibody to detect protein nitration, or (E) treated with DNPH and stained with anti-DNP to detect protein carbonylation, and counterstained with Hoechst in mice from WT $\times$ WT and WT $\times$ TgSTOX42 crosses (left panels). Right panels indicate fluorescence intensity quantification per surface (area) analyzed; identical surfaces were assessed in all samples; $n=500$ surfaces (Labyrinth), and $n=100$ surfaces (Glycogen cells, Junction zone, and Maternal cells) per tissue section. Scale bar $=50 \mu \mathrm{m}$. Quantifications are expressed as mean $\pm \mathrm{SD}$. ${ }^{*} p<0.001$ for $t$-test; $(\mathrm{WT} \times \mathrm{TgSTOX} 42 v s$. WT $\times \mathrm{WT})$. DNPH, 2, 4-dinitrophenylhydrazine; SD, standard deviation; STOX1, storkhead box 1; VDAC, voltage-dependent anion channel; WT, wild-type. To see this illustration in color, the reader is referred to the web version of this article at www.liebertpub.com/ars 


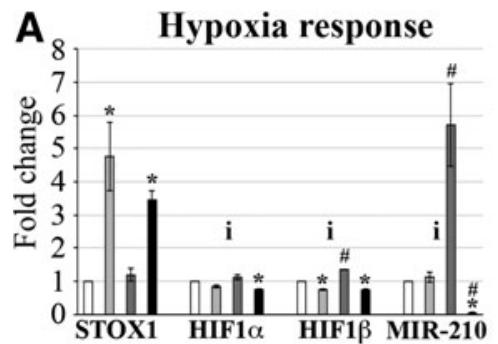

B
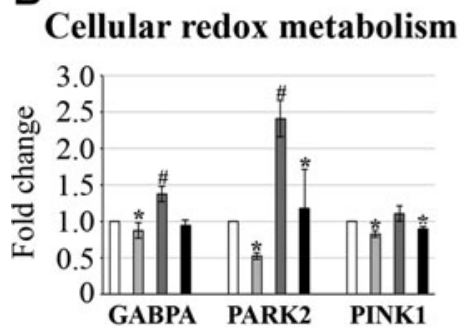

C

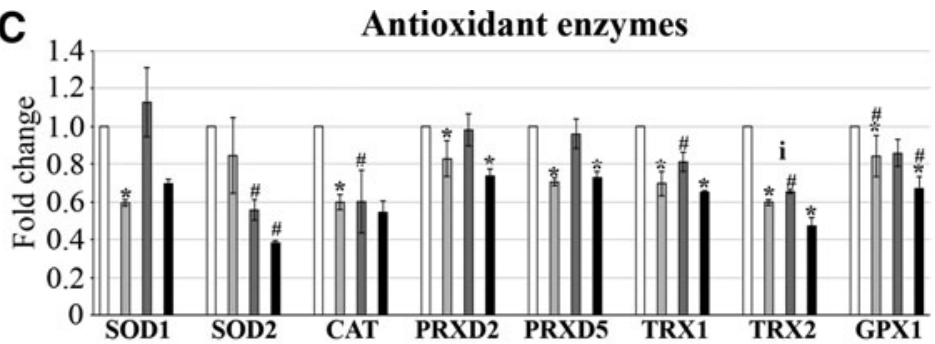

D

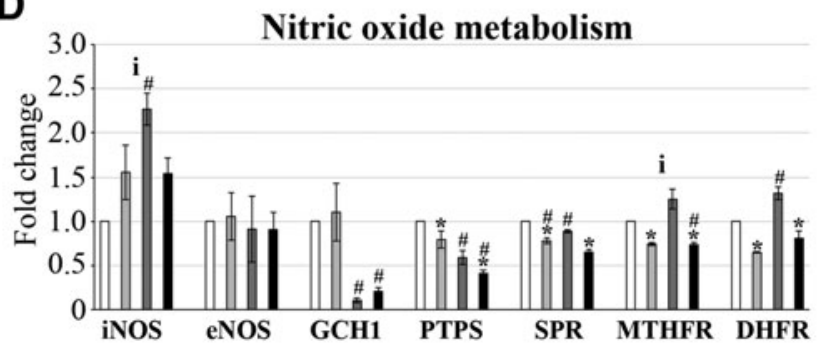

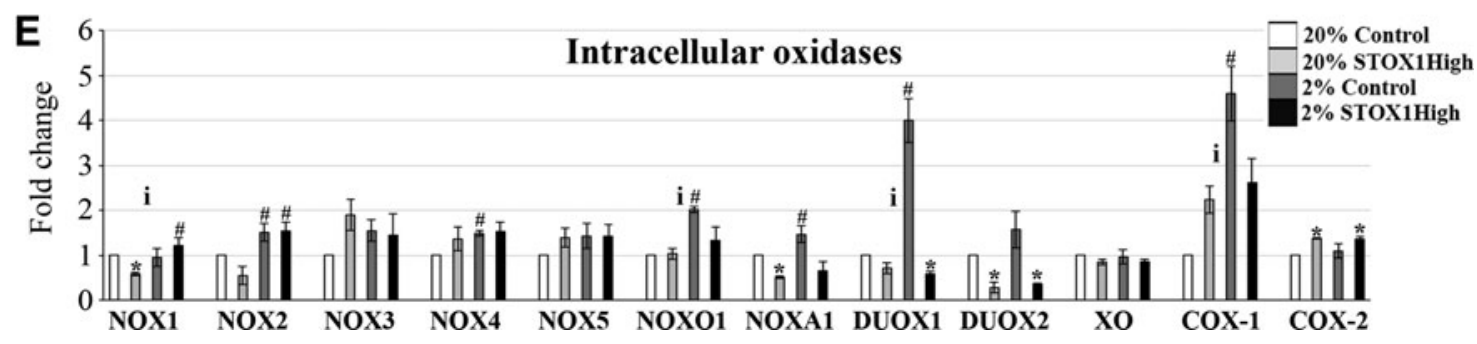

FIG. 2. Deregulation by STOX1 overexpression of the expression of genes involved in hypoxia response, antioxidant defense, and nitric oxide metabolism. Quantitative RT-qPCR measurement of key genes involved in response to hypoxia (A), antioxidant defense/cellular redox metabolism (B), antioxidant enzymes (C), nitric oxide metabolism (D), and coding for intracellular oxidases (E) in control and STOX1High cells at $20 \% \mathrm{O}_{2}$ (white and light grey bars, respectively) and at 2\% (dark gray and black bars, respectively). Statistical analysis was performed by full factorial ANOVA on two factors (oxygen concentration and STOX1 level). ${ }^{*} p<0.01$ for the effects of STOX1 expression relative to control (control cells at $\left.20 \% \mathrm{O}_{2}\right),{ }_{p} p<0.01$ for the effects of oxygen, ${ }_{p} p<0.01$ for an interaction effect, that is, for instance a differential effect of oxygen according to the STOX1 expression level. Results are expressed as mean \pm SD. Statistical details are given for each gene in Supplementary Table S4. RT-qPCR, reverse transcription quantitative PCR.

We then examined the cellular redox metabolism. Expression levels of GABPA, encoding a factor involved in mitochondrial biogenesis (7), and Parkinson protein 2 (PARK2) encoding Parkin, a E3 ubiquitin-protein ligase important for antioxidant defence (76), were increased by hypoxia in control cells, which was not the case in STOX1High cells (Fig. 2B). Furthermore, STOX1 overexpression was associated with a decrease of PINK1 expression, a mitochondrial serine/threonine protein kinase that prevents oxidative damage (26). Accordingly, most sirtuins [known to be induced in response to hypoxia (23) and to inhibit HIFmediated hypoxia response (30)], and their downstream effectors, FOXOI and FOXO3a, which are activated in the presence of oxidative stress, were highly expressed in control cells in hypoxia (19); whereas their levels were reduced in STOX1High cells at a low $\mathrm{O}_{2}$ concentration (Supplementary Fig. S2C, D). Moreover, expression levels of antioxidant enzymes that constitute the main line of defence against nitrosative and oxidative stresses (73), such as superoxide dismutases SOD1 (CU/Zn-SOD) and SOD2 (Mn-SOD), peroxiredoxins $P R D X 2$ and $P R D X 5$, thioredoxins $T R X 1$ and $T R X 2$, and glutathione peroxidase GPX1, were lower in STOX1High compared with control cells at $2 \% \mathrm{O}_{2}$ (Fig. 2C).
In addition, at $2 \% \mathrm{O}_{2}$ the hypoxia-induced expression of iNOS was repressed in STOX1High cells (Fig. 2D). STOX1 also reduced the expression of PTPS, SPR, DHFR, and $M T H F R$, encoding for enzymes involved in tetrahydrobiopterin (BH4) metabolism, which is indispensable for the transformation of L-arginine to L-citrulline and NO (75). Altogether, these observations suggest altered NO production in STOX1High compared with control cells, and particularly in hypoxia. By contrast, $S O D 2$ and $G C H 1$, which encodes an early enzyme in $\mathrm{BH} 4$ synthesis, were relatively insensitive to STOX1 but down-regulated by hypoxia (Fig. 2C, D).

The expressions of intracellular oxidases, responsible for superoxide generation and oxidative stress (5), such as the NADPH oxidase organizer 1 (NOXO1), the NOX activator 1 (NOXA1), and the dual oxidases (DUOX1 and DUOX2), were no longer induced by hypoxia when STOX1 was overexpressed (Fig. 2E). In contrast, the expression of several NOXs was mildly induced by hypoxia, while it was rather insensitive to the STOX1 status. To note, we recently reported that pre-eclamptic plasma affects NOX4 expression in endothelial cells (10). Moreover, STOX1 inhibited hypoxiainduced expression of the cyclooxygenase-1 (COX-1), and induced $C O X-2$ expression (Fig. 2E). Taken together, the 
expression of these genes indicates multiple levels of alteration of NO metabolic pathways on STOX1 overexpression, including hypoxia-dependent alterations.

In sum, under hypoxia, genes coding for enzymes implicated in free radical production are overall reduced after STOX1 overexpression; whereas the detoxifying machinery appears less active, raising questions on the physiological outcome and balance of these alterations.

\section{STOX1 overexpression affects the mitochondrial mass}

We assessed the mitochondrial mass by immunofluorescent staining of TOM22 and VDAC on fixed cells and by labeling living cells with MitoTracker Green ${ }^{\mathrm{TM}}$, a chemical dye that labels active mitochondria using the mitochondrial membrane potential (MMP) (1). These three distinct measurements showed that in control cells the mitochondrial mass was reduced in hypoxia (Fig. 3A, B and Supplementary Fig. S3, $p>0.05, p=4.4 \times 10^{-12}$, and $7.5 \times 10^{-23}$, for TOM22, VDAC, and MitoTracker, respectively, comparing $20 \% \mathrm{O}_{2}$ and hypoxia). On the contrary, in STOX1High cells, the mitochondrial mass increased about twofold in hypoxia (Fig. 3A and Supplementary Fig. S3; $p=5.1 \times 10^{-6},>0.05$ and $2.1 \times 10^{-15}$, for TOM22, VDAC, and MitoTracker, respectively comparing $20 \% \mathrm{O}_{2}$ and hypoxia).

Consistently, control cells in hypoxia showed a reduced expression of master regulators of mitochondrial biogenesis, $P G C 1 \alpha, P G C 1 \beta$, and NRF1 [but not GABPA (NRF2A) and $G A B P B 1$, Fig. $3 C$ ]. A similar decrease of $P G C 1 \beta$ and NRF1 was also observed in STOX1High cells despite increased mitochondrial mass (see Fig. 3A and Supplementary Fig. S3), suggesting that in these cells the steady-state mitochondrial mass is not primarily dependent on organelle biogenesis.

The mitochondrial mass can be reduced by autophagy, a nonselective bulk degradation of cytoplasm and organelles, or by selective autophagy (mitophagy), which eliminates damaged mitochondria and may result in cell death (54). Immunofluorescence levels of MAP1LC3B (LC3B), an autophagy factor that comprises the inactive (LC3B-I) and the autophagosome-associated active (LC3B-II) forms, were reduced by hypoxia, and the decrease was larger in STOX1High cells than in controls (Fig. 3D). Interestingly, the ratio LC3BII/LC3B-I, an indicator of autophagy activation (47), was significantly higher in STOX1High cells than in controls independently of the oxygen pressure $[1.88 \pm 0.06 v s$. $1.23 \pm 0.01$ at $20 \%$ oxygen $\left(p=2.7 \times 10^{-4}\right)$ and $1.85 \pm 0.05$ vs. $1.37 \pm 0.03$ at $2 \%$ oxygen $\left(p=7.0 \times 10^{-5}\right)$; Fig. 3E].

Global mitochondrial fragmentation, which is required before the LC3B-II-mediated mitochondria engulfment into autophagosomes in mitophagy, increased under hypoxia but was not influenced by STOX1 overexpression (Supplementary Fig. S4A). Strikingly, at $20 \% \mathrm{O}_{2}$, dynamin-related protein 1 (DRP1) (encoding a master regulator of mitochondrial fission, and inhibitor of autophagosome targeting of mitochondria) was $\sim 30$-fold lower in STOX1High cells than in control cells. DRP1 reduction may compensate for decreased mitochondrial content in STOX1High cells. By hypoxia, DRP1 expression was reduced in control cells (approximately threefold), whereas it increased in STOX1High cells (approximately ninefold) (Supplementary Fig. S4B, C). DRP1 decrease and the apparent absence of mitochondrial fragmentation suggest the inhibition of mitophagy in STOX1High cells at $20 \% \mathrm{O}_{2}$. These findings concur with decreased PARK2 expression in STOX1High cells (as shown above, in Fig. 2B, Expression of genes involved in cellular redox metabolism), PARK2 translocation to mitochondria being involved in mitophagy (76). Optic atrophy 1 (OPA1), a key regulator of mitochondrial fusion, was unaltered (Supplementary Fig. S4D, E).

In conclusion, a decrease of the mitochondrial mass in STOX1High cells at $20 \% \mathrm{O}_{2}$ may depend on activated autophagy rather than mitophagy.

\section{STOX1 overexpression affects mitochondrial function and energy metabolism}

The MMP is the driving force for mitochondrial proteins import, substrates and ions transport, and, consequently, for mitochondrial activities (49). A decrease in oxygen pressure led to a $30 \%$ reduction of MMP measured by tetramethylrhodamine ethyl ester (TMRE) fluorescence in control cells (59) (Fig. 4A), which was consistent with a decrease in mitochondrial mass (as shown above, in Supplementary Fig. S3). Conversely, STOX1High cells display the highest MMP values in hypoxia. When normalized to the mitochondrial mass (TOM22), the MMP of STOX1High cells was always higher than control cells (hypoxia $p=1.3 \times 10^{-9}, 20 \% \mathrm{O}_{2}$ $p=1 \times 10^{-4}$, Fig. 4B), indicating more mitochondrial activity in STOX1High than in control cells.

Global cellular oxidative phosphorylation capacity was assessed at $20 \% \mathrm{O}_{2}$. STOX1High cells maintained normal respiration rate and cellular adenosine triphosphate (ATP) concentration (Fig. 4C, D). Consequently, ATP levels normalized to the mitochondrial mass (TOM22) are almost threefold higher in STOX1High than in control cells (Fig. 4E). Altogether, at both $\mathrm{O}_{2}$ concentrations, mitochondria appear more active in STOX1High than in control cells.

Compared with the other conditions, STOX1High cells at $2 \% \mathrm{O}_{2}$ showed a $50 \%$ decrease of the mtDNA content (Fig. 4F), but increased levels of TFAM, a factor involved in mtDNA transcription, replication, and maintenance (Supplementary Fig. S5A-C), with an approximately fourfold higher ratio of TFAM/mtDNA. POLG, the DNA polymerase that replicates mtDNA, was affected by hypoxia (Supplementary Fig. S5D, E). Thus, STOX1High cells displayed higher levels of POLG relative to the mitochondrial mass than control cells (POLG/TOM22, 1.7-fold in hypoxia and 3.2-fold at $20 \% \mathrm{O}_{2}$ ) (Supplementary Fig. S5F).

We also evaluated mtDNA maintenance using a novel validated imaging fluorescence in situ hybridization approach, mitochondrial transcription, and replication imaging protocol (mTRIP) to assess mtDNA initiation of replication $(13,14)$. The levels of mitochondrial replication marker (mREP) (a probe that signals the D-loop opening for mtDNA replication) per cell were similar in all situations (Supplementary Fig. S5G, H), as were the levels of a mixture of probes that target several mitochondrial RNAs (mTRANS; Supplementary Fig. S6A, B). mtDNA-encoded genes were expressed at normal levels in STOX1High cells in hypoxia (Supplementary Fig. S6C) despite lower mtDNA content. Taking into account the reduced TOM22 levels, STOX1High cells at 20\% $\mathrm{O}_{2}$ displayed a two- to three-fold higher mREP and mTRANS 

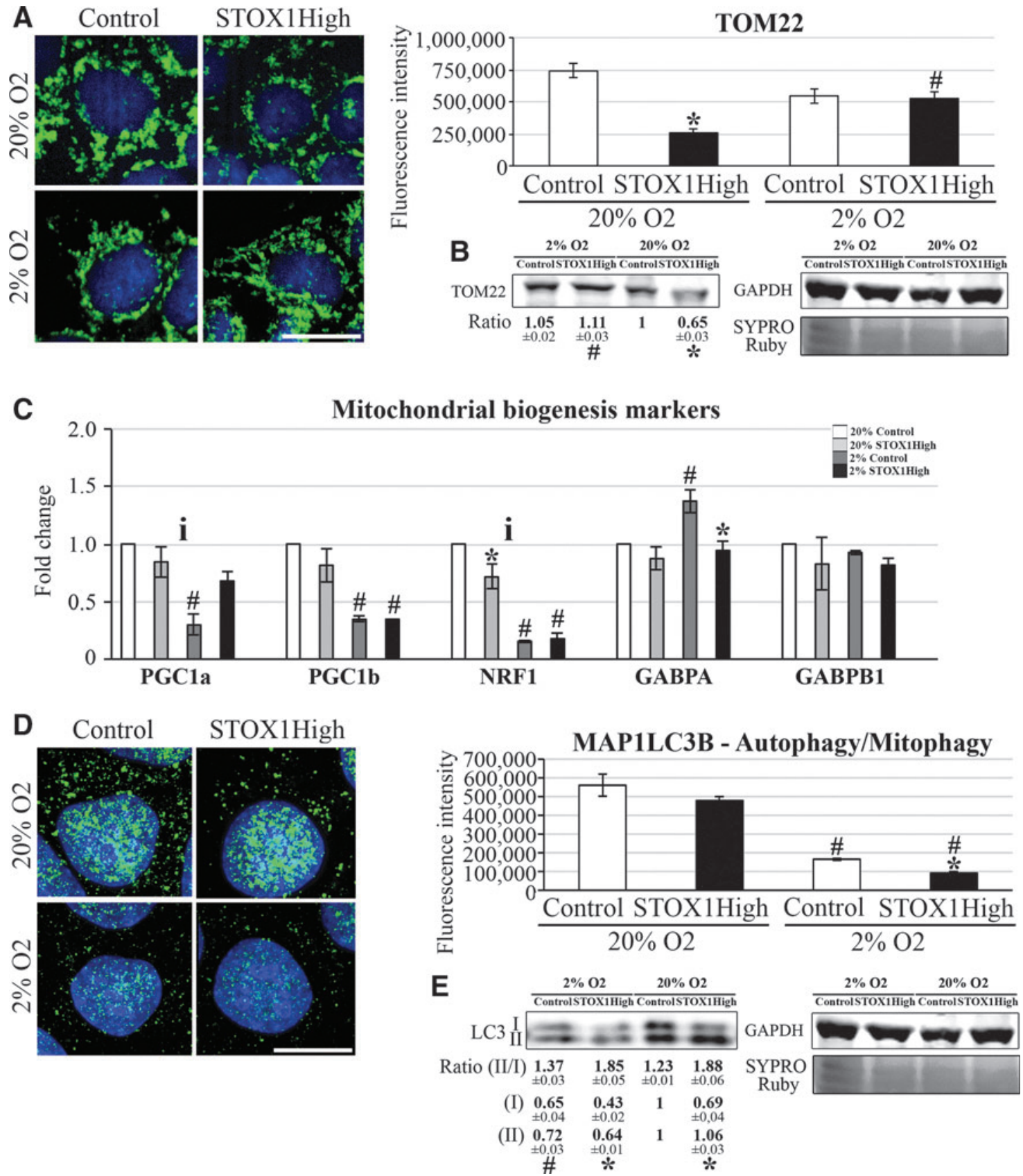

FIG. 3. Mitochondrial mass, mitochondrial biogenesis markers, and mitophagy/autophagy in STOX1 overexpressing cells. (A) Three-dimensional-reconstructed cells immunostained with anti-TOM22 (green) to detect the mitochondrial mass; nuclei are stained with Hoechst (blue). Right panel, fluorescence intensity quantification of TOM22 per cell. (B) Western blot of TOM22, internal reference GAPDH, and loading control SYPRO Ruby. The ratio of TOM22 signal normalized first to GAPDH and then to control cells at $2 \% \mathrm{O}_{2}$ is indicated; $n=3$ experiments, \pm SD. (C) Quantitative RTqPCR of mitochondrial biogenesis factors $P G C 1 \alpha, P G C 1 \beta, N R F 1, G A B P A$, and GABPB1. Statistical analysis was performed as described for Figure 2. i =interaction effect between the factor "STOX1 expression" and the factor "Hypoxia" estimated by Analysis of Variance as described in Material and Methods, section "Statistical Analysis." (D) Threedimensional-reconstructed cells immunostained with anti-MAP1LC3B (microtubule-associated proteins 1A/1B light chain 3B; or LC3B, green) and counterstained with Hoechst (blue). Right panel, fluorescence intensity quantification of MAP1LC3B per cell. (E) Western blot of inactive (I) and active (II) forms of LC3B-I, internal reference GAPDH, and loading control SYPRO Ruby. The ratio of either LC3B-I or LC3B-II signal normalized first to GAPDH and then to control cells is normalized to 1 at $20 \% \mathrm{O}_{2}$. The ratio of LC3B-II/I is calculated after normalization of the two forms to GAPDH; $n=3$ experiments, \pm SD. Scale bar $=10 \mu \mathrm{m}$. Immunofluorescence, $n=30$ cells from three independent experiments, per condition. $t$-Tests were used in these experiments; ${ }^{*} p<0.001$ STOX1High versus control cells; ${ }^{*} p<0.00120 \%$ versus $2 \% \mathrm{O}_{2}$. TOM22, LC3B, VDAC (Supplementary Fig. S3A), and GAPDH were revealed from the same blot (molecular weight, 22, 14-16, 30, and $37 \mathrm{kDa}$, respectively). Quantifications are expressed as mean \pm SD. NRF1, nuclear respiratory factor 1 . To see this illustration in color, the reader is referred to the web version of this article at www.liebertpub.com/ars 

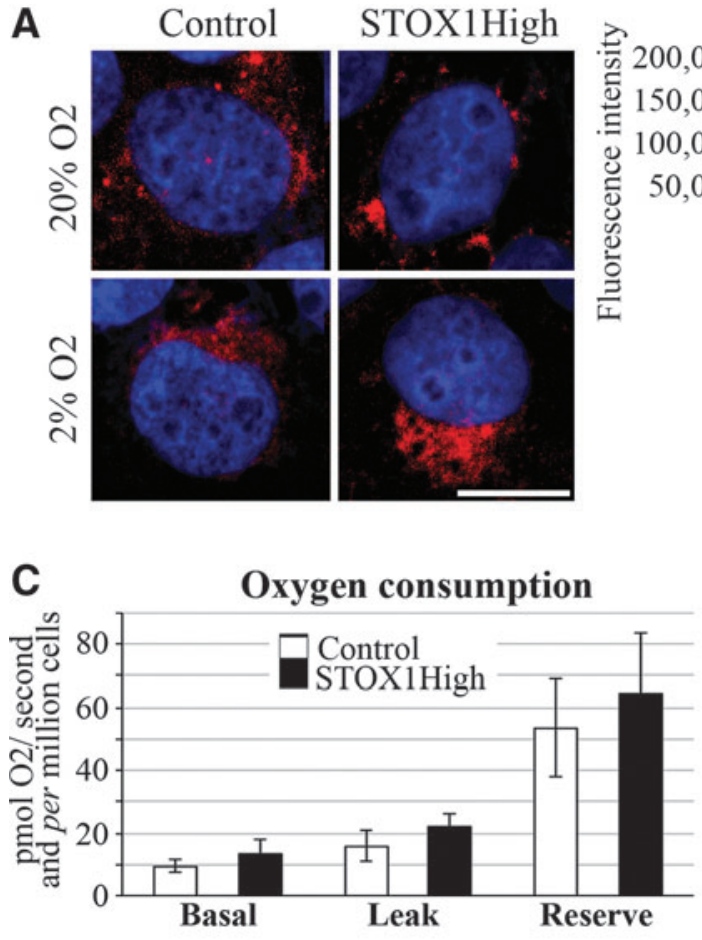

TMRE - Mitochondrial membrane potential

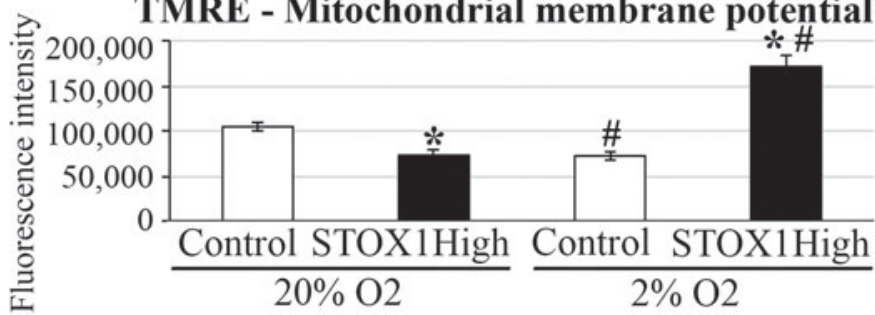

B

\begin{tabular}{|ccc|} 
Control & $20 \% \mathrm{O} 2$ & 1 \\
\hline STOX1High & $20 \% \mathrm{O2}$ & 2.00 \\
\hline Control & $\mathbf{2 \%} \mathrm{O2}$ & $\mathbf{0 . 9 4}$ \\
\hline STOX1High & $2 \% \mathrm{O2}$ & 2.30 \\
\hline
\end{tabular}

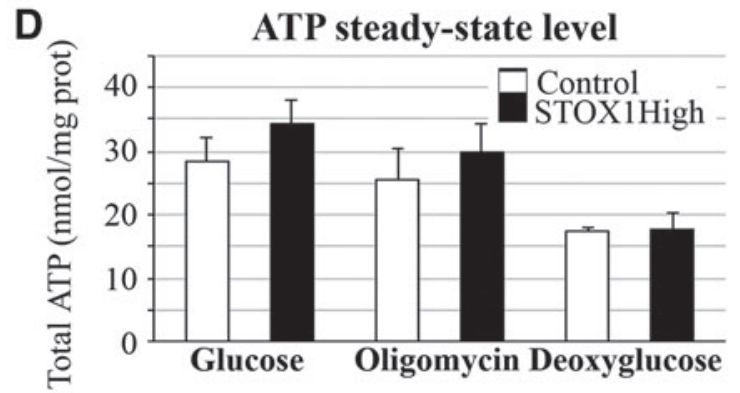

$\mathbf{E}$

\begin{tabular}{clc|} 
& \multicolumn{2}{l}{ Ratio mitoATP:TOM22 } \\
Control & $20 \%$ O2 & 1 \\
\hline STOX1High & $20 \%$ O2 & 2.92 \\
\hline
\end{tabular}

$\mathbf{F}$

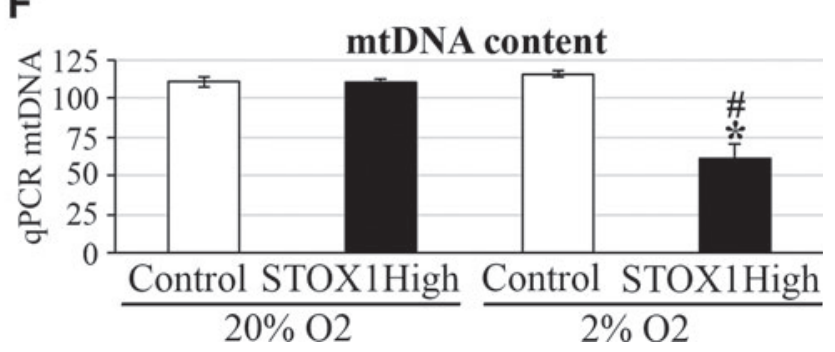

FIG. 4. Mitochondrial metabolism in STOX1 overexpressing cells. (A) Three-dimensional-reconstructed cells stained with TMRE (red) to detect the mitochondrial membrane potential; nuclei (blue) are stained with Hoechst. Right panel, fluorescence intensity quantification of TMRE per cell. $n=30$ cells from three independent experiments, per condition; scale bar $=10 \mu \mathrm{m}$. (B) Ratio of TMRE/TOM22 (for each factor, average value of three independent experiments; values of TOM22 are from Fig. 3A normalized to control cells at $20 \% \mathrm{O}_{2}$ ). (C) Oxygen consumption, pmol $\mathrm{O}_{2}$ per second and per million cells. $n=3$ experiments per condition. (D) ATP steady-state level, mmol per mg protein. $n=3$ experiments per condition. (E) Ratio of mitoATP (deoxyglucose)/TOM22 (for each factor, average value of three independent experiments; values of TOM22 are from Fig. 3A), normalized to control cells at $2 \% \mathrm{O}_{2}$. (F) MtDNA content of cells analyzed by qPCR in the $12 \mathrm{~S}$ region. $n=3$ experiments. Quantifications are expressed as mean $\pm \mathrm{SD}$. * Significant effect of STOX1, \# significant effect of $\mathrm{O}_{2}$. ATP, adenosine triphosphate; TMRE, tetramethylrhodamine ethyl ester. To see this illustration in color, the reader is referred to the web version of this article at www.liebertpub.com/ars

signal per mitochondrial mass than control cells (Supplementary Figs. S5H and S6B).

The expression of key genes involved in mtDNA maintenance and mitochondrial transcription (Supplementary Fig. S6D, E) was not correlated with the levels of mtDNA transcription. Rather, the expression of these factors increased in control cells in hypoxia, but not in STOX1High cells, indicating a failure of STOX1High cells to adapt to hypoxia by varying the expression of mtDNA processing factors.

In summary, under hypoxia, STOX1High cells maintain mitochondrial mass despite an apparent lack of adaptation. These cells display reduced mtDNA content and increased MMP. At 20\% $\mathrm{O}_{2}$, STOX1High cells maintain ATP production, $\mathrm{O}_{2}$ consumption, and mtDNA content despite reduced mitochondrial mass and MMP.
In support of the notion that hypoxia is associated with increased oxidative stress in our system, we observed alterations of key mitochondrial factors (immunofluorescence of TOM22, TFAM, POLG, and DRP1) comparable to those observed in hypoxia when STOX1High cells at 20\% Oxygen were treated with $\mathrm{H}_{2} \mathrm{O}_{2}$ (Supplementary Table S5).

\section{STOX1 overexpression induces nitroso-redox imbalance}

We then analyzed oxidative stress in STOX1High cells in hypoxia and at $20 \% \quad \mathrm{O}_{2}$ using dihydrorhodamine 123 (DHR123) and $2^{\prime}, 7^{\prime}$-dichlorofluorescein diacetate DCFHDA, two fluorescent probes with preferential sensitivity for RNS and ROS, respectively (22). In control cells, the 


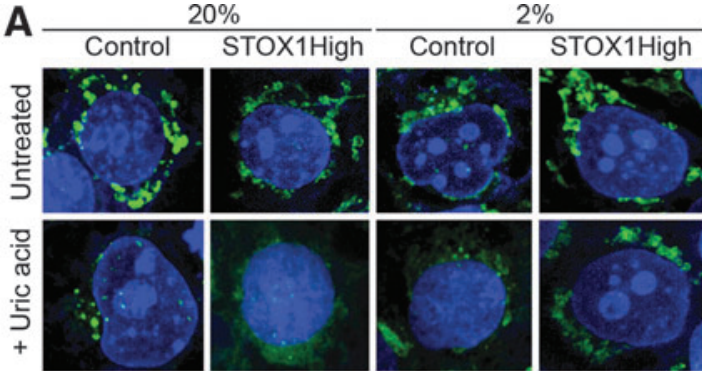

B

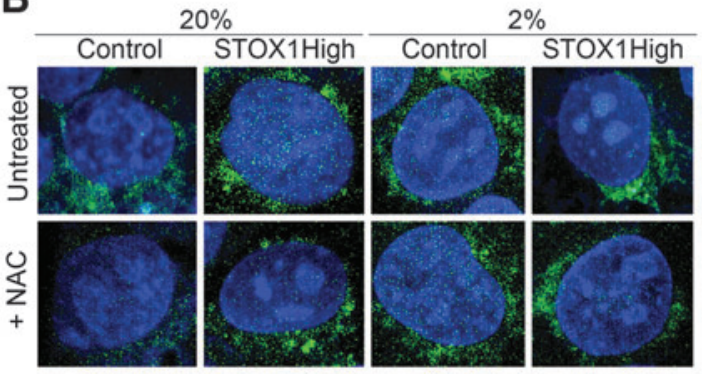

DHR123 - Peroxynitrite RNS

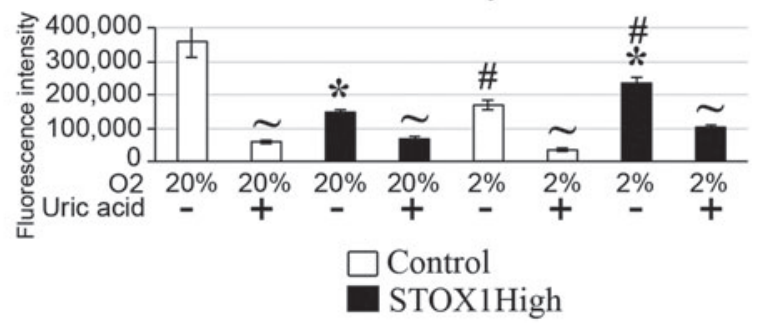

DCFH-DA - ROS

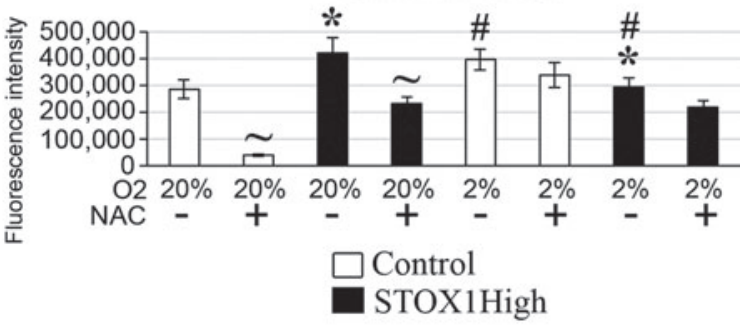

C Control STOX1High

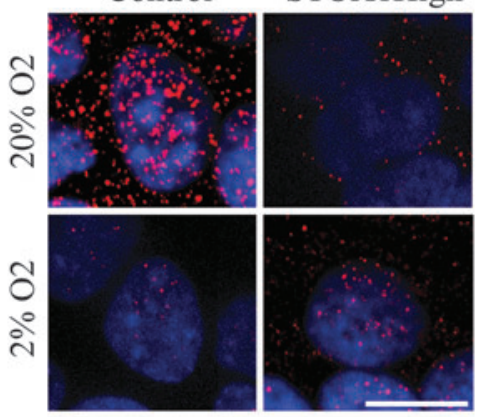

Protein nitration

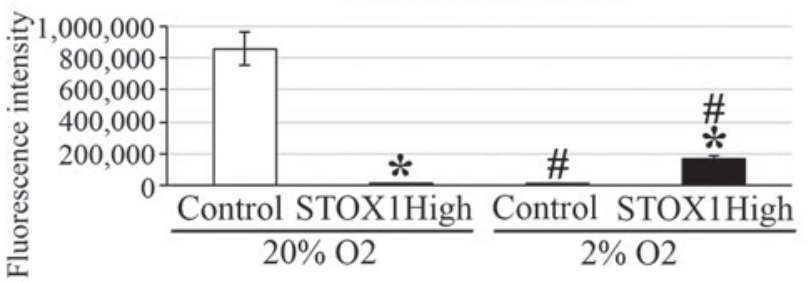

D

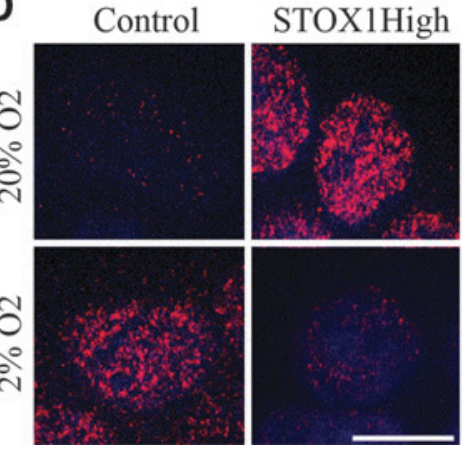

Protein carbonylation

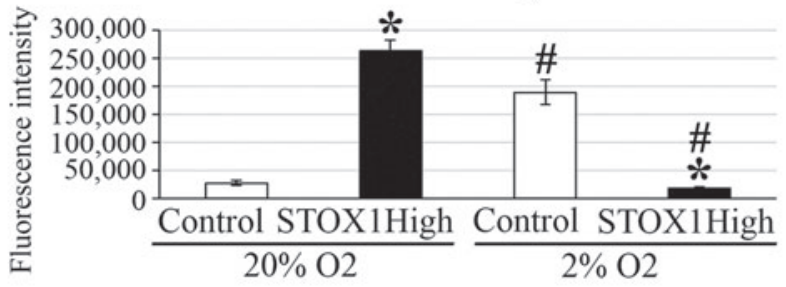

FIG. 5. Imbalanced nitroso-redox equilibrium in STOX1 overexpressing cells. (A) Three-dimensional-reconstructed cells stained with DHR123 (green) for the determination of a relative enrichment in intracellular peroxynitrites with or without treatment of the RNS scavenger uric acid at $300 \mu \mathrm{M}$. Right panel, fluorescence intensity quantification of rhodamine 123 per cell (control cells in white and STOX1High cells in black). Each experiment was performed in triplicate." $~ "$ Marks significant Student's $t$-test for the effect of each scavenger versus its absence. "\#” Marks significant oxygen effects and “*”" marks significant effect of STOX1 overexpression, in (A, B). (B) Three-dimensional-reconstructed cells stained with DCFHDA (green) for the determination of relative enrichment in intracellular ROS with or without treatment with the ROS scavenger NAC. Right panel, fluorescence intensity quantification of DCF per cell (control cells in white and STOX1High cells in black). (C) Three-dimensional-reconstructed cells stained with anti-3-nitrotyrosine (red) to detect protein nitration. Right panel, fluorescence intensity quantification of nitrated proteins per cell. (D) Three-dimensional-reconstructed cells stained with DNP and anti-DNP (red). Right panel, fluorescence intensity quantification of carbonylated proteins per cell. Nuclei are stained with Hoechst (blue). Scale bar $=10 \mu \mathrm{m} . n=30$ cells from three independent experiments per condition. Quantifications are expressed as mean \pm SD. For the Student's $t$-test: * stands for significant effect of STOX1 overexpression, \# for significant oxygen effect, and $\sim$ for significant effect of each scavenger. DCFH-DA, 2',7'-dichlorodihydrofluorescin diacetate; DHR123, dihydrorhodamine 123; NAC, $N$-acetyl cysteine; RNS, reactive nitrogen species; ROS, reactive oxygen species. To see this illustration in color, the reader is referred to the web version of this article at www.liebertpub.com/ars 
DHR123 signal increased at higher oxygen pressure; whereas the reverse was observed with DCFH-DA (Fig. 5A, B). The profile was strictly opposite in STOX1High cells. The switch from ROS to RNS signal (or vice versa) is compatible with ROS and NO competitively targeting Cys residues (42). The specificity of ROS and RNS labeling by DCFH-DA and DHR123, respectively, was analyzed at $20 \% \mathrm{O}_{2}$ and hypoxia in the presence of the RNS scavenger uric acid and the ROS inhibitor $N$-acetyl cysteine (NAC). We observed a systematic decrease of ROS and RNS labeling using the specific scavenger although, curiously, the decrease was not significant for NAC in hypoxia. It is possible that this cell line harbors resistance to NAC in hypoxia, although to our knowledge this has not been assessed. Altogether, these analyses confirm opposite ROS and RNS profiles in STOX1High versus control cells according to the oxygen pressure.

We then evaluated the steady-state levels of protein oxidative adducts, either nitration (due to RNS) or carbonylation (due to ROS) $(65,66)$ (Fig. 5C, D). STOX1High cells in hypoxia displayed a higher level of protein nitration and lower level of carbonylation than control cells, whereas the reverse pattern was observed at $20 \% \mathrm{O}_{2}$. These results were confirmed by Western blot (Supplementary Fig. S7A, B). The nitrosoredox balance, thus, appears dependent on oxygen pressure, and it is strongly modified by STOX1 overexpression.

\section{Discussion}

In the present study, we uncover a novel function of the pre-eclampsia-associated transcription factor STOX1 as a master regulator of the oxygen-dependent nitroso-redox balance. Although after the discovery of this gene the role of STOX1 in pre-eclampsia has been questioned (31), the original study (71) and a more recent one (6) concur to observe an association between STOX1 and the familial forms of pre-eclampsia. Briefly, the original study (71) identified the more abundant STOX1 Y153H polymorphism in a subpopulation of Dutch where pre-eclampsia and gestational hypertension had a strong familial component. Moreover, the study of Berends et al. (6), focusing on a "familial" subpopulation of samples, observed an association between STOX1 and the forms of pre-eclampsia with a strong familial component. In contrast, this polymorphism was not found to be associated with the disease in other populations where the pre-eclampsia was sporadic $(31,37)$. Moreover, the imprinted status of STOX1 was questioned at the global placental level (31); whereas mono-allelic methylation and expression of this gene were detected in specific cell types of the placenta (extravillous column cytotrophoblasts) (70), and an independent study showed interindividual variation in the imprinting status of STOX1 (15). In agreement with the implication of STOX1 in pre-eclampsia, overexpression of STOX1 was observed in early placental biopsies in gestations, eventually progressing to pre-eclampsia [GSE12767 in Founds et al. (20)]. Furthermore, we induced pre-eclampsialike symptoms in two independent mouse strains overexpressing STOX1 (TgSTOX13 and TgSTOX42) (18). In the present study, we focused on the strain harboring the most severe phenotype, TgSTOX42.

We show here that hypoxia affects trophoblasts in culture, and that STOX1 overexpression exacerbates this effect, thereby suggesting a double-hit model, where in excess of
STOX1, trophoblasts do not adapt to hypoxic conditions. We found a striking down-regulation of miR-210 in JEG-3 hypoxic cells overexpressing STOX1. MiR-210 is increased in pre-eclampsia; our data, thus, suggest that STOX1 overexpression mitigates an adaptive process mediated by miR210. STOX1 overexpression triggers a reduced expression of genes involved in DDR and cholesterol metabolism, two pathways that are altered in pre-eclampsia. However, the most striking effect is the imbalance of ROS and RNS induced by STOX1 overexpression in cells and placentas. The capture of NO by STOX1 overexpressing placentas is proposed here as a mechanism to explain increased blood pressure in pre-eclampsia, consistently with existing literature $(34,63)$. In human gestation, the blood flow in the placenta near term is around $600 \mathrm{ml} / \mathrm{min}$, which is theoretically able to drive a rapid and strong decrease of NO in the whole maternal body during pre-eclampsia. Modulating the ROS/RNS balance could be considered an innovative strategy to treat preeclampsia, possibly by $\mathrm{BH} 4$ treatment or uric acid precursors (60). In this case, our mouse model is a potentially excellent platform for testing therapeutic approaches in the future.

An abundant literature exists on oxidant molecules associated with pre-eclampsia (48). RNS and ROS stresses are generally treated as a whole (17). It is widely assumed that the sites of peroxynitrite generation are spatially associated with the sources of superoxide production (such as mitochondria) in the context of hypoxia and inflammation (51). Peroxynitrite ions nitrate tyrosine residues and have been shown to be elevated in pre-eclampsia (45). Peroxynitrite is associated with biological toxic effects that are also found in pre-eclampsia (62) such as antioxidant depletion (68), deregulation of COXs (3), NOS uncoupling (58), lipid peroxidation (24), insulin resistance (52), imbalance of proand anti-inflammatory mediators (12), neuro-inflammatory disease/stroke (52), DNA damage (21), mitochondrial dysfunction (50), and renal injury associated with proteinuria and high plasma uric acid level (52). Nitrotyrosine strongly marks the vasculature of pre-eclamptic placentas (8). Recently, uric acid has been reported to mark hypertension and endothelial damage in pre-eclampsia (41). Thus, uric acid could be considered a physiological protective response against peroxynitrite accumulation, as it is a natural strong peroxynitrite scavenger that inhibits inflammation (27). Peroxynitrite also affects the $\mathrm{BH} 4$ pathway and produces a vicious circle of peroxynitrite generation.

Finally, nitrosative and oxidative stresses target mitochondria (53), which we analyzed by multiple approaches, especially integrative methods of quantitative immunofluorescence $(13,14)$. At low oxygen pressure, overexpression of STOX1 did not change the mitochondrial mass in the cells, which increased in transgenic placentas, suggesting that homeostatic processes at work in the organs are absent in the cells. This discrepancy is consistent with recent literature (43). Similarly, VDAC was found to be increased by proteomic analysis in the pre-eclamptic placenta (36), which is consistent with our data (Fig. 1C); whereas it was not altered in cells at low oxygen pressure and even reduced at high oxygen pressure.

Views of the immunohistochemical alterations that characterize the control versus STOX1High cells are presented as a Principal Component Analysis in Figure 6A. Control cells at $2 \% \mathrm{O}_{2}$ present intermediate features between STOX1 High cells at $2 \%$ and $20 \% \mathrm{O}_{2}$, suggesting that STOX1 

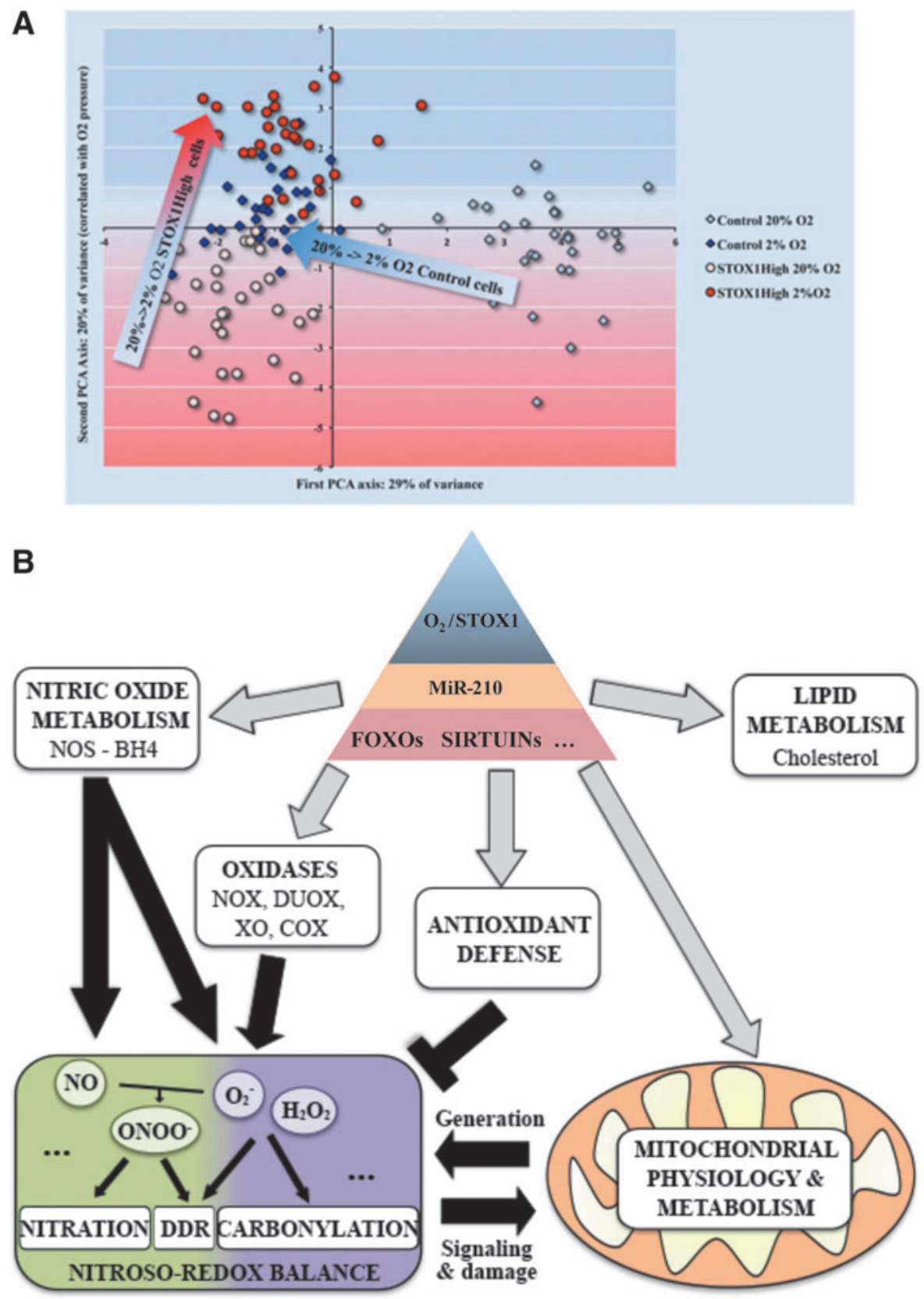

FIG. 6. Meta-analysis of STOX1 overexpressing cells. (A) Principal Component Analysis with the quantitative immunofluorescence data from peroxynitrite, ROS, protein nitration, protein carbonylation, TOM22, TFAM, mtDNA content, POLG, mREP, mTRANS, OPA1, DRP1, LC3B, and TMRE. The two first axes represent more than $49 \%(29 \%+20 \%)$ of the overall variation. It clearly appears that STOX1High cells are not able to respond adequately to hypoxia and are close to control cells which are already in hypoxic conditions. (B) Proposed model in normal physiology and pre-eclampsia/STOX1 overexpressing cells representing the cellular and molecular bases of the effects of STOX1 (see also text). First, for many genes, the effects of STOX1 depend on the oxygen pressure, as shown by significant interaction effects. STOX1 overexpression down-regulates the expression of key hypoxia regulators, such as $H I F 1 \alpha, H I F 1 \beta$ and drastically miR-210, possibly inducing a defective response to hypoxia both in vitro and in vivo. Key transcription factors, including FOXOs and Sirtuins, that are involved in lipid metabolism, nitric oxide metabolism, oxidases, antioxidant defense, and mitochondrial function are dramatically altered. The combined deregulation of these factors and STOX1 overexpression affect the nitric oxide metabolism [NOS uncoupling, NO bioavailability, and $\mathrm{ONOO}^{-}$generation: alteration of $\mathrm{BH} 4$ destabilizes $\mathrm{NOS}$, which uncoupled, will alternatively produce $\mathrm{O}_{2}-$ and $\mathrm{NO}$, and form highly reactive peroxynitrite ions $\left.\left(\mathrm{ONOO}^{-}\right)\right](2,75)$, oxidant generation $\left(\mathrm{O}_{2}-\right)$, antioxidant defense, mitochondrial function and metabolism, DDR, and cholesterol metabolism. This analysis suggests a mechanism by which STOX1 overexpression activates a powerful NO pump that may deprive the maternal endothelium of this molecule, thereby contributing to the pre-eclamptic phenotype. DDR, DNA damage response. BH4, tetrahydrobiopterin; DRP1, dynamin-related protein 1; mREP, mitochondrial replication marker; mTRANS, a mixture of probes that target several mitochondrial RNAs; NOS, nitric oxide synthase; OPA1, optic atrophy 1; POLG, polymerase (DNA directed), gamma; TFAM, transcription factor A, mitochondrial. To see this illustration in color, the reader is referred to the web version of this article at www.liebertpub.com/ars 
overexpression interferes with oxygen sensors and somehow putting the cells in an artificial "hypoxic" state.

In agreement with these findings, and underscoring the misregulation of oxidative stress management when STOX1 is overexpressed, we observed comparable effects on mitochondrial factors in STOX1High cells grown either under hypoxia or at $20 \% \mathrm{O}_{2}$ in the presence of the highly oxidizing factor $\mathrm{H}_{2} \mathrm{O}_{2}$. Moreover, in the presence of $\mathrm{H}_{2} \mathrm{O}_{2}$, STOX1High cells displayed a global increase of mitochondrial parameters; whereas it was the opposite for control cells.

In hypoxia, STOX1High cells contain a damaging and toxic cocktail with accumulation of peroxynitrite and relatively high level of ROS. The mtDNA content is reduced but appears highly protected by TFAM, and the mitochondrial mass is not affected, probably resulting from the balance between increased mitochondrial biogenesis (marker PGC1 $\alpha$ ) and increased level of the autophagy (LC3B-II/I). At high oxygen pressure, STOX1High cells have nearly the same damaging cocktail except that peroxynitrite levels decrease and the ROS levels increase. The mitochondrial mass is also dramatically reduced due to a strong increase of LC3B, which activates autophagy, and to DRP1 deficiency. However, to maintain stable total ATP level, the remaining mitochondria appear hyper-activated (increased membrane (Fig. 6B) potential, increased mtDNA replication, and transcription levels per mitochondrial mass unit). This led us to a model (Fig. 6B) presenting cellular and molecular bases of STOX1 effects in the context of mitochondrial function and pre-eclampsia.

\section{Materials and Methods}

\section{Mouse placentas and microarray experiment}

Four- to eight-month-old male and female mice with the FVB/N genetic background were used throughout this study, bred in the animal facility of Institut National de Recherche Agronomique (INRA, Jouy en Josas, France) in a controlled environment (light/dark cycle, temperature, free access to food and water) in accordance with local ethical regulations. RNA was extracted from placentas in TriZol ${ }^{\mathrm{TM}}$ following classical protocols at $16.5 \mathrm{dpc}$ from three different mice of each group as previously described (18). Quality control of the RNA, preparation of the probes, and hybridization on Nimblegen Mouse Expression Arrays MM8 were performed at the genom'IC platform (Cochin Institute, Paris, France) according to standard protocols. Data from this experiment, fulfilling the Minimum Information About a Microarray Experiment (MIAME) criteria, were deposited in the functional genomics ArrayExpress database of the EMBL-EBI web server (accession number E-MTAB-1970). Data were analyzed using GSEA (www.broadinstitute.org/gsea/index.jsp). This program compares the experimental dataset with a series of pathways (67), analyzes the distribution of the genes of the dataset present in the given pathways, and tests by simulation the randomness of their distribution. Generally, the program is set to a FDR of 0.25 .

\section{Cell culture and hypoxia}

Modified JEG-3 cells (control cells, stably transfected with an empty pCMX vector, and STOX1High cells, stably transfected with a pCMX-STOX1A vector) (56) were grown in Dulbecco's modified Eagle's medium Glutamax (Life
Technologies ${ }^{\mathrm{TM}}$, Carlsbad, CA) with $10 \%$ of heat-inactivated fetal calf serum (Life Technologies), $1 \%$ penicillin/streptomycin, and $1 \%$ of geneticin at $37^{\circ} \mathrm{C}$ in the presence of $5 \%$ $\mathrm{CO}_{2}$. Cells seeded overnight in wells containing glass dishes, on sterile glass slides, were placed in a Lwoff chamber at $37^{\circ} \mathrm{C}$ and exposed to an oxygen-depleted atmosphere for $24 \mathrm{~h}$ $\left(2 \% \mathrm{O}_{2}, 5 \% \mathrm{CO}_{2}\right)$ or maintained at $37^{\circ} \mathrm{C}$ in a humidified normal atmosphere $\left(20 \% \mathrm{O}_{2}, 5 \% \mathrm{CO}_{2}\right)$ for $24 \mathrm{~h}$. The experiments were performed independently thrice, each in triplicate. When indicated, cells were grown in $20 \% \mathrm{O}_{2}$ in the presence of $150 \mu \mathrm{m} \mathrm{H} \mathrm{H}_{2}$ for $24 \mathrm{~h}$.

\section{Reverse transcription quantitative polymerase chain reaction}

Total RNA was isolated and reverse transcribed according to standard protocols. RT-qPCR was performed using LightCycler ${ }^{\circledR} 480$ SYBR Green I Master containing FastStart Taq DNA Polymerase, and the rate of dye incorporation was monitored using a LightCycler 480 Instrument II and the LightCycler software (Roche, Basel, Switzerland) in the exponential phase of the PCR reaction. Each RT-qPCR was carried out in technical duplicates from a pool of three biological replicates, using TBP transcript levels for normalization. RT-qPCR CT values were analyzed using the $2^{-\Delta \Delta C T}$ method to calculate the fold expression (40). Primers used for amplifications are listed in Supplementary Table S3 with the corresponding references.

Quantification of miRNA-210 followed the protocol of Sdassi et al. (61). A polyA tail was added to RNA by Poly-A polymerase treatment (Life Technologies). After phenolchloroform treatment in the presence of glycogen as a carrier, and isopropanol precipitation, reverse transcription was carried out from a universal primer 5'-CGAATTCTAGA GCTCGAGGCAGGCGACATGGCTGGCTAGTTAAGCT TGGTACCGAGCTCGGATCCACTAGTCCTTTTTTTTT TTTTTTTTTTTTTTTTTVN-3'. Quantitative PCR was performed using the Universal and miR-210-specific primers (5'-CGAATTCTAGAGCTCGAGGCAGG-3' and 5'CTGTGCGTGTGACAGCGGCTGA-3', which is identical for humans and mice), using 5S RNA as a reporter gene.

\section{mtDNA content analysis by $q P C R$}

DNA was extracted under standard procedures. Quantitative PCR was performed in duplicates from three biological replicates using LightCycler 480 SYBR Green I Master containing FastStart Taq DNA Polymerase, LightCycler 480 Instrument II, and LightCycler software (Roche). The region tested on mtDNA was included in the $12 \mathrm{~S}$ gene. $18 \mathrm{~S}$ rRNA gene was used as a reference. The level of mtDNA was calculated using the $\triangle \mathrm{CT}$ of average $\mathrm{CT}$ of $\mathrm{mtDNA}$ and nuclear DNA $(\triangle \mathrm{CT}=\mathrm{CT}$ nDNA-CT mtDNA) as $2 \Delta \mathrm{CT}$. Primers used for amplifications are listed in Supplementary Table S3.

\section{Immunofluorescence, reagents, and antibodies}

Cells seeded on slides were fixed with $2 \%$ paraformaldehyde (PFA) and permeabilized with $0.5 \%$ Triton X-100. Slides were incubated in blocking buffer ( $5 \%$ bovine serum albumin [BSA] in phosphate-buffered saline [PBS]) overnight at $4^{\circ} \mathrm{C}$, then with the primary antibody for $1 \mathrm{~h}$ at room temperature (RT), and, finally, with the secondary antibody 
and $10 \mu \mathrm{g} / \mathrm{ml}$ of Hoechst 33342 for $1 \mathrm{~h}$ at RT. Atto488-conjugated anti-TOM22, anti-MAP1LC3B, and Hoechst 33342 were from Sigma-Aldrich (St Louis, MI); TFAM, Pol $\gamma$, VDAC 1/2/3 (sc-98708), OPA1, DRP1, and GAPDH antibodies were from SantaCruz Biotechnology (Dallas, TX); and MitoTracker ${ }^{\circledR}$ Green FM, Alexa ${ }^{\circledR}$ Fluor 555, and Alexa ${ }^{\circledR}$ Fluor 488-conjugated secondary antibodies were from Life Technologies.

MMP was measured with $200 \mathrm{n} M$ TMRE (Sigma-Aldrich) for $1 \mathrm{~h}$ at $37^{\circ} \mathrm{C}, 5 \% \mathrm{CO}_{2}$, and $2 \%$ or $20 \% \mathrm{O}_{2}$.

Immunohistochemistry of placentas was performed on WT or transgenic placentas (expressing the human STOX1 under the control of the cytomegalovirus promoter) (18). Mice were sacrificed near the end of gestation (E16.5). Four WT placentas from two $(\mathrm{WT} \times \mathrm{WT})$ crosses and seven placentas from four $(\mathrm{WT} \times \mathrm{TgSTOX} 42)$ crosses were analyzed for TOM22 immunofluorescence, and for protein nitration and carbonylation. Placental regions, ascertained by periodic acid Schiff staining of adjacent sections, were analyzed by immunostaining on slides from paraffin-embedded placentas $(5 \mu \mathrm{m})$. Placental sections were dewaxed in $2 \%$ DishWasher Soap, $1 \times \mathrm{PBS}$ for $5 \mathrm{~min}$ at $70^{\circ} \mathrm{C}$, and then prepared according to the specific immunofluorescence procedure.

\section{Detection of peroxynitrite, ROS, and protein oxidation and carbonylation}

Peroxynitrite was detected after treatment of the cells at $10 \mu M$ of the cell-permeant nonfluorescent DHR123 (SigmaAldrich) oxidized in green fluorescent rhodamine in the presence of peroxynitrite. ROS (mainly $\mathrm{O}_{2}-$ and $\mathrm{H}_{2} \mathrm{O}_{2}$ ) were detected after treatment with $10 \mu M$ of the cell-permeable nonfluorescent 2',7'-dichlorodihydrofluorescin diacetate (DCFH-DA; Sigma), oxidized to form green fluorescent $2^{\prime}, 7^{\prime}$-dichlorofluorescein (DCF), in the presence of ROS (16).

Protein nitration was detected with the 3-nitrotyrosinespecific antibody (Ref: A21285; Life Technologies/Invitrogen). Protein carbonylation was detected by dinitrophenyl treatment, followed by labeling with the DNP-specific antibody using standard procedures (44). Slides were treated with $0.01 \%(100 \mu \mathrm{g} / \mathrm{ml})$ 2,4-dinitrophenylhydrazine (DNPH) (Sigma-Aldrich) in $2 \mathrm{~N} \mathrm{HCl}$ for $1 \mathrm{~h}$ at $\mathrm{RT}$ in the dark, washed seven times with PBS, blocked with $5 \%$ BSA in PBS overnight at $4^{\circ} \mathrm{C}$, then treated with the primary anti-DNP antibody (Merck Millipore, Darmstadt, Germany) for $1 \mathrm{~h}$ at RT, and, finally, with the secondary antibody and $10 \mu \mathrm{g} / \mathrm{ml}$ of Hoechst 33342 for $1 \mathrm{~h}$ at RT. When mentioned, the cells were treated for $24 \mathrm{~h}$ with uric acid (300 $\mu M$ final), or with NAC ( $2 \mathrm{mM}$ final), both of which had been purchased from Sigma-Aldrich.

\section{Mitochondrial transcription and replication imaging protocol}

DNA probes (mREP and mTRANS) for the fluorescence in situ hybridization protocol called mTRIP were labeled by nick translation of PCR products, incorporating Atto550dUTP (Atto550 NT Labeling kit; Jena Bioscience, Jena, Germany), as described (14). Forty nanograms of labeled probes were mixed with $400 \mathrm{ng}$ of sonicated salmon sperm DNA (Sigma-Aldrich) in the hybridization buffer [50\% formamide, $10 \%$ dextran sulfate, in $2 \times$ saline-sodium citrate (SSC) buffer $\mathrm{pH} 7.0]$, denatured at $80^{\circ} \mathrm{C}$ for $10 \mathrm{~min}$, and then maintained at $37^{\circ} \mathrm{C}$ for $30 \mathrm{~min}$. Cells seeded on slides were fixed with $2 \%$ PFA, permeabilized with $0.5 \%$ Triton $X-100$, incubated in $50 \%$ formamide $/ 2 \times \mathrm{SSC} \mathrm{pH} 7.0$ for $30 \mathrm{~min}$ at RT, and denaturated in $70 \%$ formamide $/ 2 \times \mathrm{SSC}$ for $4 \mathrm{~min}$ at $75^{\circ} \mathrm{C}$. Hybridization was performed with $40 \mathrm{ng}$ of probe for $16 \mathrm{~h}$ at $37^{\circ} \mathrm{C}$. Slides were washed in SSC, and nuclei were counterstained with $10 \mu \mathrm{g} / \mathrm{ml}$ of Hoechst 33342 .

\section{Three-dimensional confocal acquisition, reconstruction, and quantification}

Confocal acquisition was performed using an inverted laser-scanning confocal microscope Zeiss Axiovert $200 \mathrm{M}$ with a spinning-disk Perkin-Elmer Ultraview RS Nipkow Disk, an Apochromat $63 \times / 1.4$ oil objective for fixed cells or an $25 \times$ oil objective for mice placenta section, and a Hamamatsu ORCAII-ER camera (Imagopole, PFID; Institut Pasteur, Paris, France). Optical slices were taken every 200-nm interval along the $\mathrm{z}$-axis covering the whole depth of the cell, at a resolution of 1.024/1.024 pixels. Three-dimensinal reconstruction was achieved using the IMARIS software (Bitplane, South Windsor, CT). Post-acquisition analysis and fluorescence quantification were done using a single-imaging frame collection and ImageJ $1.38 \times$ software. For each sample, 30 cells were analyzed from three independent experiments.

\section{Oxygen consumption and total ATP steady-state level}

High-resolution respirometry was performed on 106 intact cells per ml of culture medium at $20 \% \mathrm{O}_{2}$ (38). Subsequent sequential additions were as follows: $0.5 \mu \mathrm{g} / \mathrm{ml}$ oligomycin to measure leaks, successive $1 \mu M$ doses of the protonophore carbonyl cyanide m-chlorophenyl hydrazone (cccp) up to the maximal respiration rate, and, finally, $1 \mathrm{~m} M \mathrm{KCN}$ to evaluate nonrespiratory oxygen consumption. Reserve respiration was defined as the difference between maximal and basal respiration rate.

ATP steady-state level was measured by the ATP chemiluminescent assay (Roche, Mannheim, Germany) and normalized to the amount of cellular protein. Cells were incubated in the culture medium (basal) for $15 \mathrm{~h}$ with $1 \mu M$ oligomycin to inhibit mitochondrial ATP synthesis or without glucose but with $10 \mathrm{~m} M$ deoxyglucose to inhibit glycolysis.

\section{Protein extraction and immunoblot}

Cells were lysed in $50 \mathrm{~m} M$ Tris- $\mathrm{HCl} \mathrm{pH} 7.5,150 \mathrm{~m} M$ $\mathrm{NaCl}, 1 \%$ Triton $\mathrm{X}-100,0.1 \%$ sodium dodecyl sulfate (SDS), $1 \mathrm{~m} M$ EDTA, and protease inhibitor cocktail. Thirty micrograms of protein, estimated by Bradford reactions (SigmaAldrich), were loaded for SDS-PAGE. After blotting, Hybond ECL nitrocellulose filters were probed with primary antibodies, then with IRDye secondary antibodies. Detection was performed using Odyssey Infrared Imaging system scanner and Odyssey application software v3.0 (LI-COR Biosciences, Lincoln, NE). OPA1, DRP1, and TFAM (Supplementary Fig. S5) were revealed from the same blot as well as GAPDH and the loading test by SYPRO Ruby (molecular weight, 92, 80, 28, and $37 \mathrm{kDa}$, respectively).

Protein bands were quantified, normalized to GAPDH, and then normalized to control cells grown at $20 \% \mathrm{O}_{2}$. Since GAPDH may vary under hypoxia, a second normalization was done with SYPRO Ruby Protein Blot Stain according to the manufacturer's protocol (Life Technologies). Experiments 
were done in triplicate, and a representative Western blot was presented. For the carbonylated protein level (DNPH derivatization), the protein extracts were treated according to the protocol of OxyBlot Protein Oxidation Detection Kit (Merck Millipore).

\section{Statistical analysis}

Statistical tests were performed using StatistiXL, a package running as an Add-in to Windows versions of Microsoft's Excel spreadsheet program. The RT-qPCR experiments were analyzed by Full Factorial ANOVA. The detailed statistical results are given in Supplementary Table S4 for 81 genes analyzed. The effect of STOX1 is reported as "STOX1 status," the effect of Oxygen ( $2 \%$ or $20 \%$ ) as "Oxygen status," and the possible interaction between the two factors as "Oxygen status*Stox 1 status." For immunohistochemistry and Western blots, Student's $t$-tests were performed. In the figures, significant effects of oxygen are represented with the symbol "\#," whereas significant effects of STOX1 overexpression are indicated with the symbol "**." Significant interaction effects are indicated by "i.",

Multidimensional analyses (Principal Component Analysis) were performed on quantifications of fluorescent data, for building Figure 6A.

In this study, $p<0.001$ was considered significant for immunohistochemistry and Western blot experiments; $p<0.01$ for RT-qPCR and qPCR (for mitochondrial DNA content).

\section{Acknowledgments}

The authors thank the "Imagopole" (PFID) of Institut Pasteur. This work was supported by Agence Nationale de la Recherche (ANR 11 BSV2 025 02), Association pour la Recherche sur le Cancer (ARC SFI20111204038), and Association Française contre les Myopathies (AFM 16290). L.D. was a recipient of a $\mathrm{PhD}$ fellowship from the Ecole Normale Supérieure (Paris). A.D. was a PhD fellow from the Doctoral School GC2ID.

\section{Author Disclosure Statement}

The authors declare no conflict of interest.

\section{References}

1. Agnello M, Morici G, and Rinaldi AM. A method for measuring mitochondrial mass and activity. Cytotechnology 56: 145-149, 2008.

2. Alp NJ and Channon KM. Regulation of endothelial nitric oxide synthase by tetrahydrobiopterin in vascular disease. Arterioscler Thromb Vasc Biol 24: 413-420, 2004.

3. Bachawaty T, Washington SL, and Walsh SW. Neutrophil expression of cyclooxygenase 2 in preeclampsia. Reprod Sci 17: 465-470, 2010.

4. Bartha JL, Visiedo F, Fernandez-Deudero A, Bugatto F, and Perdomo G. Decreased mitochondrial fatty acid oxidation in placentas from women with preeclampsia. Placenta 33: 132-134, 2012.

5. Bedard K and Krause KH. The NOX family of ROSgenerating NADPH oxidases: physiology and pathophysiology. Physiol Rev 87: 245-313, 2007.

6. Berends AL, Bertoli-Avella AM, de Groot CJ, van Duijn $\mathrm{CM}$, Oostra BA, and Steegers EA. STOX1 gene in pre- eclampsia and intrauterine growth restriction. BJOG 114: 1163-1167, 2007.

7. Bishayee A, Bhatia D, Thoppil RJ, Darvesh AS, Nevo E, and Lansky EP. Pomegranate-mediated chemoprevention of experimental hepatocarcinogenesis involves Nrf2regulated antioxidant mechanisms. Carcinogenesis 32: 888-896, 2011.

8. Bosco C, Gonzalez J, Gutierrez R, Parra-Cordero M, Barja $\mathrm{P}$, and Rodrigo $\mathrm{R}$. Oxidative damage to pre-eclamptic placenta: immunohistochemical expression of VEGF, nitrotyrosine residues and von Willebrand factor. J Matern Fetal Neonatal Med 25: 2339-2345, 2012.

9. Broughton Pipkin F. Risk factors for preeclampsia. $N$ Engl J Med 344: 925-926, 2001.

10. Calicchio R, Buffat C, Mathieu JR, Ben Salem N, Mehats C, Jacques S, Hertig A, Berkane N, Grevoul-Fresquet J, Simeoni U, Peyssonnaux C, Gavard J, Vaiman D, and Miralles F. Preeclamptic plasma induces transcription modifications involving the AP-1 transcriptional regulator JDP2 in endothelial cells. Am J Pathol 183: 1993-2006, 2013.

11. Caniggia I and Winter JL. Adriana and Luisa Castellucci Award lecture 2001. Hypoxia inducible factor-1: oxygen regulation of trophoblast differentiation in normal and preeclamptic pregnancies-a review. Placenta 23 Suppl A: S47-S57, 2002.

12. Catarino C, Santos-Silva A, Belo L, Rocha-Pereira P, Rocha S, Patricio B, Quintanilha A, and Rebelo I. Inflammatory disturbances in preeclampsia: relationship between maternal and umbilical cord blood. J Pregnancy 2012: 684384, 2012.

13. Chatre L and Ricchetti M. Large heterogeneity of mitochondrial DNA transcription and initiation of replication exposed by single-cell imaging. J Cell Sci 126: 914-926, 2012.

14. Chatre L and Ricchetti M. Prevalent coordination of mitochondrial DNA transcription and initiation of replication with the cell cycle. Nucleic Acids Res 41: 3068-3078, 2013.

15. Cheung VG, Bruzel A, Burdick JT, Morley M, Devlin JL, and Spielman RS. Monozygotic twins reveal germline contribution to allelic expression differences. Am J Hum Genet 82: 1357-1360, 2008.

16. Deng T, Xu K, Zhang L, and Zheng X. Dynamic determination of Ox-LDL-induced oxidative/nitrosative stress in single macrophage by using fluorescent probes. Cell Biol Int 32: 1425-1432, 2008.

17. Domann FE. Aberrant free radical biology is a unifying theme in the etiology and pathogenesis of major human diseases. Int J Mol Sci 14: 8491-8495, 2013.

18. Doridot L, Passet B, Mehats C, Rigourd V, Barbaux S, Ducat A, Mondon F, Vilotte M, Castille J, Breuiller-Fouche M, Daniel N, le Provost F, Bauchet AL, Baudrie V, Hertig A, Buffat C, Simeoni U, Germain G, Vilotte JL, and Vaiman D. Preeclampsia-like symptoms induced in mice by fetoplacental expression of STOX1 are reversed by aspirin treatment. Hypertension 61: 662-668, 2013.

19. Eijkelenboom A and Burgering BM. FOXOs: signalling integrators for homeostasis maintenance. Nat Rev Mol Cell Biol 14: 83-97, 2013.

20. Founds SA, Conley YP, Lyons-Weiler JF, Jeyabalan A, Allen Hogge W, and Conrad KP. Altered global gene expression in first trimester placentas of women destined to develop preeclampsia. Placenta 30: 15-24, 2009. 
21. Fujimaki A, Watanabe K, Mori T, Kimura C, Shinohara K, and Wakatsuki A. Placental oxidative DNA damage and its repair in preeclamptic women with fetal growth restriction. Placenta 32: 367-372, 2011.

22. Gomes A, Fernandes E, and Lima JL. Fluorescence probes used for detection of reactive oxygen species. $J$ Biochem Biophys Methods 65: 45-80, 2005.

23. Guarani V and Potente M. SIRT1: a metabolic sensor that controls blood vessel growth. Curr Opin Pharmacol 10: 139-145, 2010.

24. Gupta S, Aziz N, Sekhon L, Agarwal R, Mansour G, Li J, and Agarwal A. Lipid peroxidation and antioxidant status in preeclampsia: a systematic review. Obstet Gynecol Surv 64: 750-759, 2009.

25. Heazell AE, Moll SJ, Jones CJ, Baker PN, and Crocker IP. Formation of syncytial knots is increased by hyperoxia, hypoxia and reactive oxygen species. Placenta 28 Suppl A: S33-S40, 2007.

26. Hoepken HH, Gispert S, Morales B, Wingerter O, Del Turco D, Mulsch A, Nussbaum RL, Muller K, Drose S, Brandt U, Deller T, Wirth B, Kudin AP, Kunz WS, and Auburger G. Mitochondrial dysfunction, peroxidation damage and changes in glutathione metabolism in PARK6. Neurobiol Dis 25: 401-411, 2007.

27. Hooper DC, Scott GS, Zborek A, Mikheeva T, Kean RB, Koprowski H, and Spitsin SV. Uric acid, a peroxynitrite scavenger, inhibits CNS inflammation, blood-CNS barrier permeability changes, and tissue damage in a mouse model of multiple sclerosis. FASEB J 14: 691-698, 2000.

28. Houtkooper RH, Pirinen E, and Auwerx J. Sirtuins as regulators of metabolism and healthspan. Nat Rev Mol Cell Biol 13: 225-238, 2012.

29. Hsu P, Santner-Nanan B, Dahlstrom JE, Fadia M, Chandra A, Peek M, and Nanan R. Altered decidual DC-SIGN+ antigen-presenting cells and impaired regulatory T-cell induction in preeclampsia. Am J Pathol 181: 2149-2160, 2012.

30. Hubbi ME, Hu H, Kshitiz, Gilkes DM, and Semenza GL. Sirtuin-7 inhibits the activity of hypoxia-inducible factors. J Biol Chem 288: 20768-20775, 2013.

31. Iglesias-Platas I, Monk D, Jebbink J, Buimer M, Boer K, van der Post J, Hills F, Apostolidou S, Ris-Stalpers C, Stanier P, and Moore GE. STOX1 is not imprinted and is not likely to be involved in preeclampsia. Nat Genet 39: 279-280, 2007.

32. Ishibashi O, Ohkuchi A, Ali MM, Kurashina R, Luo SS, Ishikawa T, Takizawa T, Hirashima C, Takahashi K, Migita $\mathrm{M}$, Ishikawa $\mathrm{G}$, Yoneyama $\mathrm{K}$, Asakura $\mathrm{H}$, Izumi A, Matsubara S, and Takeshita T. Hydroxysteroid (17-beta) dehydrogenase 1 is dysregulated by miR-210 and miR-518c that are aberrantly expressed in preeclamptic placentas: a novel marker for predicting preeclampsia. Hypertension 59: 265-273, 2012.

33. Jauniaux E, Gulbis B, and Burton GJ. Physiological implications of the materno-fetal oxygen gradient in human early pregnancy. Reprod Biomed Online 7: 250-253, 2003.

34. Johal T, Lees CC, Everett TR, and Wilkinson IB. The nitric oxide pathway and possible therapeutic options in preeclampsia. Br J Clin Pharmacol 2013. DOI: 10.1111/ bcp. 12301 .

35. Kaufmann P, Black S, and Huppertz B. Endovascular trophoblast invasion: implications for the pathogenesis of intrauterine growth retardation and preeclampsia. Biol Reprod 69: 1-7, 2003.
36. Kim YN, Kim HK, Warda M, Kim N, Park WS, Prince Adel B, Jeong DH, Lee DS, Kim KT, and Han J. Toward a better understanding of preeclampsia: comparative proteomic analysis of preeclamptic placentas. Proteomics Clin Appl 1: 1625-1636, 2007.

37. Kivinen K, Peterson H, Hiltunen L, Laivuori H, Heino S, Tiala I, Knuutila S, Rasi V, and Kere J. Evaluation of STOX1 as a preeclampsia candidate gene in a populationwide sample. Eur J Hum Genet 15: 494-497, 2007.

38. Kuznetsov AV, Strobl D, Ruttmann E, Konigsrainer A, Margreiter R, and Gnaiger E. Evaluation of mitochondrial respiratory function in small biopsies of liver. Anal Biochem 305: 186-194, 2002.

39. Latil M, Rocheteau P, Chatre L, Sanulli S, Memet S, Ricchetti M, Tajbakhsh S, and Chretien F. Skeletal muscle stem cells adopt a dormant cell state post mortem and retain regenerative capacity. Nat Commun 3: 903, 2012.

40. Livak $\mathrm{K}$ and Schmittgen $\mathrm{T}$. Analysis of relative gene expression data using real-time quantitative PCR and the 2DDCt method. Methods 25: 402-408, 2001.

41. Loeffler LF, Navas-Acien A, Brady TM, Miller ER 3rd, and Fadrowski JJ. Uric acid level and elevated blood pressure in US adolescents: National Health and Nutrition Examination Survey, 1999-2006. Hypertension 59: 811-817, 2012.

42. Lounifi I, Arc E, Molassiotis A, Job D, Rajjou L, and Tanou G. Interplay between protein carbonylation and nitrosylation in plants. Proteomics 13: 568-578, 2013.

43. Mando C, De Palma C, Stampalija T, Anelli GM, Figus M, Novielli C, Parisi F, Clementi E, and Ferrazzi E, Cetin I. Placental mitochondrial content and function in intrauterine growth restriction and preeclampsia. Am J Physiol Endocrinol Metab, 2013.

44. Mathew SS, Bryant PW, and Burch AD. Accumulation of oxidized proteins in Herpesvirus infected cells. Free Radic Biol Med 49: 383-391, 2010.

45. Mazzanti L, Cecati M, Vignini A, D'Eusanio S, Emanuelli M, Giannubilo SR, Saccucci F, and Tranquilli AL. Placental expression of endothelial and inducible nitric oxide synthase and nitric oxide levels in patients with HELLP syndrome. Am J Obstet Gynecol 205: 236.e1-e7, 2011.

46. Mazzanti L, Raffaelli F, Vignini A, Nanetti L, Vitali P, Boscarato V, Giannubilo SR, and Tranquilli AL. Nitric oxide and peroxynitrite platelet levels in gestational hypertension and preeclampsia. Platelets 23: 26-35, 2012.

47. Melser S, Chatelain EH, Lavie J, Mahfouf W, Jose C, Obre E, Goorden S, Priault M, Elgersma Y, Rezvani HR, Rossignol R, and Benard G. Rheb regulates mitophagy induced by mitochondrial energetic status. Cell Metab 17: 719-730, 2013.

48. Mishra N, Nugent WH, Mahavadi S, and Walsh SW. Mechanisms of enhanced vascular reactivity in preeclampsia. Hypertension 58: 867-873, 2011.

49. Mitra K, Wunder C, Roysam B, Lin G, and LippincottSchwartz J. A hyperfused mitochondrial state achieved at G1-S regulates cyclin E buildup and entry into $\mathrm{S}$ phase. Proc Natl Acad Sci U S A 106: 11960-11965, 2009.

50. Muralimanoharan S, Maloyan A, Mele J, Guo C, Myatt LG, and Myatt L. MIR-210 modulates mitochondrial respiration in placenta with preeclampsia. Placenta 33: 816-823, 2012.

51. Myatt L. Review: reactive oxygen and nitrogen species and functional adaptation of the placenta. Placenta 31 Suppl: S66-S69, 2010.

52. Noris M, Perico N, and Remuzzi G. Mechanisms of disease: pre-eclampsia. Nat Clin Pract Nephrol 1: 98-114, 2005; quiz 120. 
53. Poyton RO, Ball KA, and Castello PR. Mitochondrial generation of free radicals and hypoxic signaling. Trends Endocrinol Metab 20: 332-340, 2009.

54. Rabinowitz JD and White E. Autophagy and metabolism. Science 330: 1344-1348, 2010.

55. Rajakumar A, Cerdeira AS, Rana S, Zsengeller Z, Edmunds L, Jeyabalan A, Hubel CA, Stillman IE, Parikh SM, and Karumanchi SA. Transcriptionally active syncytial aggregates in the maternal circulation may contribute to circulating soluble fms-like tyrosine kinase 1 in preeclampsia. Hypertension 59: 256-264, 2012.

56. Rigourd V, Chauvet C, Chelbi ST, Rebourcet R, Mondon F, Letourneur F, Mignot TM, Barbaux S, and Vaiman D. STOX1 overexpression in choriocarcinoma cells mimics transcriptional alterations observed in preeclamptic placentas. PLoS One 3: e3905, 2008.

57. Roberts JM and Hubel CA. Is oxidative stress the link in the two-stage model of pre-eclampsia? Lancet 354: 788-789, 1999.

58. Sankaralingam S, Xu H, and Davidge ST. Arginase contributes to endothelial cell oxidative stress in response to plasma from women with preeclampsia. Cardiovasc Res 85: 194-203, 2010.

59. Scaduto RC Jr., and Grotyohann LW. Measurement of mitochondrial membrane potential using fluorescent rhodamine derivatives. Biophys J 76: 469-477, 1999.

60. Schmidt TS, McNeill E, Douglas G, Crabtree MJ, Hale AB, Khoo J, O'Neill CA, Cheng A, Channon KM, and Alp NJ. Tetrahydrobiopterin supplementation reduces atherosclerosis and vascular inflammation in apolipoprotein E-knockout mice. Clin Sci (Lond) 119: 131-142, 2010.

61. Sdassi N, Silveri L, Laubier J, Tilly G, Costa J, Layani S, Vilotte JL, and Le Provost F. Identification and characterization of new miRNAs cloned from normal mouse mammary gland. BMC Genomics 10: 149, 2009.

62. Serdar Z, Gur E, Colakoethullary M, Develioethlu O, and Sarandol E. Lipid and protein oxidation and antioxidant function in women with mild and severe preeclampsia. Arch Gynecol Obstet 268: 19-25, 2003.

63. Sertorio JT, Lacchini R, Amaral LM, Palei AC, Cavalli RC, Sandrim VC, Duarte G, and Tanus-Santos JE. Haptoglobin polymorphism affects nitric oxide bioavailability in preeclampsia. J Hum Hypertens 27: 349-354, 2013.

64. Shi Z, Long W, Zhao C, Guo X, Shen R, and Ding H. Comparative proteomics analysis suggests that placental mitochondria are involved in the development of preeclampsia. PLoS One 8: e64351, 2013.

65. Shimizu K, Ogawa F, Muroi E, Hara T, Komura K, Bae SJ, and Sato $\mathrm{S}$. Increased serum levels of nitrotyrosine, a marker for peroxynitrite production, in systemic sclerosis. Clin Exp Rheumatol 25: 281-286, 2007.

66. Sibai BM. Thrombophilia and severe preeclampsia: time to screen and treat in future pregnancies? Hypertension 46: 1252-1253, 2005.

67. Subramanian A, Tamayo P, Mootha VK, Mukherjee S, Ebert BL, Gillette MA, Paulovich A, Pomeroy SL, Golub TR, Lander ES, and Mesirov JP. Gene set enrichment analysis: a knowledge-based approach for interpreting genome-wide expression profiles. Proc Natl Acad Sci U S A 102: 15545-15550, 2005.

68. Szabo C. Hydrogen sulphide and its therapeutic potential. Nat Rev Drug Discov 6: 917-935, 2007.

69. Szabo C, Ischiropoulos H, and Radi R. Peroxynitrite: biochemistry, pathophysiology and development of therapeutics. Nat Rev Drug Discov 6: 662-680, 2007.
70. van Dijk M, Drewlo S, and Oudejans CB. Differential methylation of STOX1 in human placenta. Epigenetics 5: 736-742, 2010.

71. van Dijk M, Mulders J, Poutsma A, Konst AA, Lachmeijer AM, Dekker GA, Blankenstein MA, and Oudejans CB. Maternal segregation of the Dutch preeclampsia locus at 10q22 with a new member of the winged helix gene family. Nat Genet 37: 514-519, 2005.

72. Wang Y and Walsh SW. Placental mitochondria as a source of oxidative stress in pre-eclampsia. Placenta 19: 581-586, 1998.

73. Wassmann S, Wassmann K, and Nickenig G. Modulation of oxidant and antioxidant enzyme expression and function in vascular cells. Hypertension 44: 381-386, 2004.

74. Webster RP, Brockman D, and Myatt L. Nitration of p38 MAPK in the placenta: association of nitration with reduced catalytic activity of p38 MAPK in pre-eclampsia. Mol Hum Reprod 12: 677-685, 2006.

75. Werner ER, Blau N, and Thony B. Tetrahydrobiopterin: biochemistry and pathophysiology. Biochem J 438: 397414, 2011.

76. Youle RJ and Narendra DP. Mechanisms of mitophagy. Nat Rev Mol Cell Biol 12: 9-14, 2011.

Address correspondence to: Dr. Daniel Vaiman

Department of Development, Reproduction, and Cancer Institut Cochin

INSERM U1016

24 Rue du Faubourg St. Jacques Paris 75014

France

E-mail: daniel.vaiman@inserm.fr

Dr. Miria Ricchetti Unité de Génétique Moléculaire des Levures Institut Pasteur

25 Rue du Docteur Roux Paris 75724 cedex 15 France

E-mail: mricch@pasteur.fr

Date of first submission to ARS Central, October 16, 2013; date of final revised submission, April 7, 2014; date of acceptance, April 14, 2014.

$\begin{aligned} & \text { Abbreviations Used } \\ \mathrm{ATP} & =\text { adenosine triphosphate } \\ \mathrm{BH} 4 & =\text { tetrahydrobiopterin } \\ \mathrm{BSA} & =\text { bovine serum albumin } \\ \mathrm{COX} & =\text { cyclooxygenase } \\ \mathrm{DCFH}-\mathrm{DA} & =2^{\prime}, 7^{\prime} \text {-dichlorodihydrofluorescin diacetate } \\ \mathrm{DDR} & =\text { DNA damage response } \\ \mathrm{DHFR} & =\text { dihydrofolate reductase } \\ \mathrm{DHR} 123 & =\text { dihydrorhodamine } 123 \\ \mathrm{DNPH} & =2,4 \text {-dinitrophenylhydrazine } \\ \mathrm{DRP} 1 & =\text { dynamin related protein } 1 \\ \mathrm{DUOX} & =\text { dual oxidase } \\ \mathrm{FDR} & =\text { false discovery rate } \\ \mathrm{FOXO} 1 & =\text { forkhead box protein } \mathrm{O} 1\end{aligned}$




\section{Abbreviations Used (Cont.)}

$\mathrm{FOXO} 3 \mathrm{a}=$ forkhead box protein $\mathrm{O} 3 \mathrm{a}$

$\mathrm{GABPA}=\mathrm{GA}$-binding protein transcription factor, alpha subunit $60 \mathrm{kDa}$

$\mathrm{GABPB} 1=\mathrm{GA}$-binding protein transcription factor, beta subunit 1

$\mathrm{GCH} 1=\mathrm{GTP}$ cyclohydrolase 1

GSEA $=$ Gene Set Enrichment Analysis

$\mathrm{HIF}=$ hypoxia-inducible factor

iNOS $=$ nitric oxide synthase 2 , inducible

MAP1LC3B $=$ microtubule-associated protein 1 light chain 3 beta

MMP $=$ mitochondrial membrane potential

$\mathrm{mREP}=$ mitochondrial replication marker (labeling D-loop opening)

MTHFR $=$ methylenetetrahydrofolate reductase $(\mathrm{NAD}(\mathrm{P}) \mathrm{H})$

mTRANS $=$ a mixture of probes that target several mitochondrial RNAs

$\mathrm{mTRIP}=$ mitochondrial transcription and replication imaging protocol

$\mathrm{NAC}=N$-acetyl cysteine

$\mathrm{NO}=$ nitric oxide

NOS $=$ nitric oxide synthase

$\mathrm{NOX}=\mathrm{NADPH}$ oxidase

NOXA $1=$ NOX activator 1

NOXO1 $=$ NADPH oxidase organizer 1

$\mathrm{NRF} 1=$ nuclear respiratory factor 1

$\mathrm{NRF} 2 \mathrm{~A}=\mathrm{GABPA}$, GA-binding protein transcription factor, alpha subunit $60 \mathrm{kDa}$

OPA1 = optic atrophy 1 (autosomal dominant)

PAGE $=$ polyacrylamide gel electrophoresis

PARK2 $=$ Parkinson protein 2, E3 ubiquitin protein ligase (Parkin)

PBS $=$ phosphate-buffered saline

$\mathrm{PFA}=$ paraformaldehyde
PGC1 $\alpha=$ peroxisome proliferator-activated receptor gamma, coactivator 1 alpha

$\operatorname{PGC} 1 \beta=$ peroxisome proliferator-activated receptor gamma, coactivator 1 beta

PINK1 $=$ PTEN-induced putative kinase 1

$\mathrm{POLG}=$ polymerase (DNA directed), gamma

PRDX2 = peroxiredoxin 2

PRDX5 $=$ peroxiredoxin 5

PTPS $=6$-pyruvoyltetrahydropterin synthase

$\mathrm{RNS}=$ reactive nitrogen species

$\mathrm{ROS}=$ reactive oxygen species

$\mathrm{RT}=$ room temperature

$\mathrm{RT}-\mathrm{PCR}=$ reverse transcription quantitative polymerase chain reaction

$\mathrm{SD}=$ standard deviation

SDS $=$ sodium dodecyl sulfate

sENG $=$ soluble endoglin

sFLT $-1=$ soluble fms-related tyrosine kinase 1

SOD2 = superoxide dismutase 2, mitochondrial $\mathrm{SPR}=$ sepiapterin reductase

(7,8-dihydrobiopterin:NADP ${ }^{+}$ oxidoreductase)

SREBP1A = sterol regulatory element binding transcription factor 1 , isoform $\mathrm{A}$

SREBP1C $=$ sterol regulatory element binding transcription factor 1 , isoform $\mathrm{C}$

$\mathrm{SSD}=$ saline-sodium citrate

STOX1 $=$ storkhead box 1

TFAM $=$ transcription factor A, mitochondrial

TMRE $=$ tetramethylrhodamine ethyl ester

TOM22 $=$ translocase of outer mitochondrial membrane 22 homolog (yeast)

TRX1 $=$ thioredoxin 1

TRX2 $=$ thioredoxin 2

$\mathrm{VDAC}=$ voltage-dependent anion channel

$\mathrm{WT}=$ wild-type 